\title{
Hydrazine selective decomposition over metal free carbonaceous
}

\section{materials}

\author{
Ilaria Barlocco ${ }^{a}$, Silvio Bellomi ${ }^{a}$, Simone Tumiatic ${ }^{c}$ Nikolaos Dimitratos ${ }^{d}$, Alberto Roldan*b, Patrizia \\ Fumagallic, Alberto Villa*a \\ ${ }^{a}$ Dipartimento di Chimica, Università degli Studi di Milano, via Golgi 19, I-20133Milano, Italy \\ ${ }^{b}$ Cardiff Catalysis Institute, School of Chemistry, Cardiff University, Main Building, Park Place, CF10 3AT, \\ Cardiff, United Kingdom \\ 'Dipartimento di Scienze della Terra "Ardito Desio", Università degli Studi di Milano, via Mangiagalli 34, I- \\ 20133 Milano, Italy
}

${ }^{\mathrm{d}}$ Dipartimento di Chimica Industriale e dei Materiali, ALMA MATER STUDIORUM Università di Bologna, Viale Risorgimento 4, 40136 Bologna, Italy

${ }^{*}$ Corresponding authors

E-mail addresses: Alberto.Villa@unimi.it (A.Villa), RoldanMartinezA@cardiff.ac.uk (A. Roldan)

\section{$\underline{\text { Abstract }}$}

Herein we report a combined experimental and computational investigation unravelling the hydrazine hydrate decomposition reaction on metal-free catalysts. The study focuses on commercial graphite and two different carbon nanofibers, Pyrolytically Stripped (CNF-PS) and High Heat-Treated (CNF-HHT), respectively treated at 700 and $3000{ }^{\circ} \mathrm{C}$ to increase their intrinsic defects. Raman spectroscopy demonstrated a correlation between the initial catalytic activity and the intrinsic defectiveness of the carbonaceous materials. The CNFs-PS higher defectivity $\left(\mathrm{I}_{\mathrm{D}} / \mathrm{I}_{\mathrm{G}}=1.54\right)$ leads to the most performing metal-free catalyst, showing a hydrazine conversion of $94 \%$ after 6 hours of reaction and a selectivity to $\mathrm{H}_{2}$ of the $89 \%$. In addition, to unveil the role of $\mathrm{NaOH}$ CNFs-PS were also tested in absence of alkaline solution, showing a decreasing in the reaction rate. Density functional theory (DFT) demonstrated that the single vacancies (SV) present on the graphitic layer is the only active site promoting the hydrazine decomposition, whereas other defects such as double vacancy (DV) and Stone-Wales defects (SW) are unable to adsorb hydrazine fragments. Two symmetrical and one asymmetrical dehydrogenation pathways were found, in addition to an incomplete decomposition pathway forming $\mathrm{N}_{2}$ and $\mathrm{NH}_{3}$. On the most stable hydrogen production pathway, the effect of the alkaline medium was elucidated through calculations concerning the diffusion and recombination of atomic hydrogen. Indeed, the presence of $\mathrm{NaOH}$ helps extracting $\mathrm{H}$ species without additional energetic barriers, as opposed to the calculations performed in polarizable continuum medium. Considering the initial hydrazine dissociative adsorption, the first step of the dehydrogenation pathway is the more favourable than the scission of the $\mathrm{N}-\mathrm{N}$ bond, which lead to $\mathrm{NH}_{3}$ as product. This first reaction step is crucial to define the reaction mechanisms and the computational results are in agreement with the experimental ones. Moreover, comparing two different hydrogen production pathways (with and without diffusion and recombination), we confirmed that the presence of sodium hydroxide in the experimental reaction environment can modify the energy gap between the two pathways, leading to an increased reaction rate and selectivity to $\mathrm{H}_{2}$. 
Keywords: Hydrogen, Ammonia, Hydrazine decomposition, metal-free catalysts, carbon fibers.

\section{$\underline{\text { Introduction }}$}

Green and sustainable sources of energy are essential to mitigate the environmental impact of fossil fuels and the rising energy demand. Hydrogen have been recognised as one of the most suitable alternative energy vectors due to its high energy and innocuous products upon utilisation [1]. Even though its benefits, hydrogen direct usage is inhibited by the scarcity of economically and safe hydrogen storage technologies [2]. Hence, alternative approaches to store and transport it [3-6], and materials that release hydrogen under mild condition, are urgently required [7].

Hydrazine $\left(\mathrm{N}_{2} \mathrm{H}_{4}\right)$ can be employed as hydrogen carrier because it is liquid at $\mathrm{T}<114^{\circ} \mathrm{C}(1 \mathrm{~atm})$ and can be easily transported [8-11]. In addition, it is a carbon-free fuel, hence avoiding undesired emissions, e.g. $\mathrm{CO}_{2}$, and species damaging the catalysts as seen in $\mathrm{CO}$ poisoning $\mathrm{Pt} / \mathrm{C}$ electrodes in proton exchange membrane fuel cells (PEMFCs) $[12,13]$. Currently, the $\mathrm{N}_{2} \mathrm{H}_{4}$ exothermic decomposition is employed as a propellant in aerospace application, i.e., in rockets and artificial satellites [14,15]. $\mathrm{N}_{2} \mathrm{H}_{4}$ possesses an hydrogen content of $12.5 \mathrm{wt} \%$ [16] and decomposes into a mixture of ammonia, hydrogen and nitrogen in the presence of catalysts such as Shell 405 (30 wt \% Ir/ $\left.\mathrm{Al}_{2} \mathrm{O}_{3}\right)[17,18]$. $\mathrm{N}_{2} \mathrm{H}_{4}$ decomposition occurs into two different pathways [19-21]:

$$
\begin{gathered}
\left.\mathrm{N}_{2} \mathrm{H}_{4} \rightarrow \mathrm{N}_{2}(\mathrm{~g})+2 \mathrm{H}_{2}(\mathrm{~g}) \quad \Delta \mathrm{H}=-95.4 \mathrm{KJ} \cdot \mathrm{mol}^{-1} \quad \text { (Eq. } 1\right) \\
3 \mathrm{~N}_{2} H_{4} \rightarrow N_{2}(g)+4 \mathrm{NH}_{3}(g) \quad \Delta \mathrm{H}=-157.0 \mathrm{KJ} \cdot \mathrm{mol}^{-1} \quad \text { (Eq. 2) }
\end{gathered}
$$

The first reaction (Eq. 1) represents the complete reforming pathway, where molecular hydrogen and nitrogen are produced. The second reaction (Eq. 2) is thermodynamically favoured and produces ammonia and nitrogen. The selectivity of the reaction can vary with the reaction conditions, such as pressure, temperature and catalyst presence [22-25]. In a typical hydrazine catalytic decomposition process on metal surfaces, the molecule adsorbs on catalyst surface (below marked with and asterisk) driving the N-N or the $\mathrm{N}-\mathrm{H}$ cleavage. From a thermodynamic point of view, the cleavage of the N-N bond (Eq. 3) is favoured compared to the $\mathrm{N}-\mathrm{H}$ bond dissociation energy (BDE, Eq. 4) $[26,27]$ Hence, the nature of the catalyst plays a crucial role in quenching the incomplete decomposition pathway (Eq. 2) and promoting the cleavage of N-H bond (Eq. 4).

$$
\begin{array}{rc}
\mathrm{N}_{2} \mathrm{H}_{4}^{*} \rightarrow H_{2} \mathrm{~N}^{*}+H_{2} \mathrm{~N}^{*} & \text { BDE }=286.0 \mathrm{KJ} . \mathrm{mol}^{-1} \quad(E q .3) \\
\mathrm{N}_{2} H_{4}^{*} \rightarrow H_{3} N_{2}^{*}+H^{*} & \text { BDE }=360.0 \mathrm{KJ} . \mathrm{mol}^{-1} \quad(E q .4)
\end{array}
$$

Because of its hypergolic nature, the risk of explosion is one of the most serious problem related to handling hydrazine, especially in the presence of a metal that may catalyse its decomposition [28]. One solution can be the dilution of $\mathrm{N}_{2} \mathrm{H}_{4}$ in inert gas such as argon [25] or in water, forming hydrous hydrazine $\left(\mathrm{N}_{2} \mathrm{H}_{4} \cdot \mathrm{H}_{2} \mathrm{O}\right)$, which can be particularly important as a liquid hydrogen source [29]. Hydrous hydrazine still contains $7.9 \mathrm{wt}$ $\%$ of hydrogen, avoiding all the issues related to $\mathrm{H}_{2}$ storage and transportation $[7,30]$. The development of a catalyst capable to exothermically react with $\mathrm{N}_{2} \mathrm{H}_{4} \cdot \mathrm{H}_{2} \mathrm{O}$ and selectively decompose it into hydrogen is key for a $\mathrm{H}_{2}$-based economy $[26,31]$. In order to generate hydrogen in a controlled manner and on-demand, different supported [32-34] and unsupported metal NPs have been investigated [13,15,28]. At first, noble metals such as Ir [29,35] and Rh [10,36] performed well as reforming catalyst. Nevertheless, due to the cost and synergetic catalytic properties, $\mathrm{Ni}$ was introduced as second metal providing superior activity and selectivity [33,37-43]. 
The presence of $\mathrm{NaOH}$ in the hydrazine decomposition environment can favour its selective decomposition, suppressing the formation of $\mathrm{NH}_{3}$. In particular, Wang et al. have demonstrated that adding a $0.5 \mathrm{M}$ solution of $\mathrm{NaOH}$ to unsupported Ni nanoparticles (NPs) can enhance the selectivity to $\mathrm{H}_{2}$ from $64 \%$ to $100 \%$ [44]. In addition, Peng and co-workers have performed theoretical and experimental studies on $\mathrm{Pt}-\mathrm{Ni} / \mathrm{C}$ catalysts showing a strong dependence of the selectivity and reaction rate with the $\mathrm{pH}$ [45]. Indeed, the presence of $\mathrm{OH}^{-}$facilitates the $\mathrm{N}-\mathrm{H}$ scission and promotes the $\mathrm{H}_{2}$ and $\mathrm{H}_{2} \mathrm{O}$ formation $[11,46]$.

Despite the excellent activity, selectivity and stability of metal-based catalysts [27,47-51], employing metals is raising reservations about the overall sustainability of hydrogen production reactions [52-54]. On the other hand, in the last few decades, carbon-based catalysts are attracting significant attention on replacing metalbased materials in heterogeneous catalysis. Different studies have demonstrated that metal-free carbon materials can be effective in gas phase reactions, in particular for alkenes and alkanes dehydrogenation [5557], and in liquid phase reactions, i.e., oxidation of benzene [58] and alcohols [59,60], and reductions such as acetylene, carbon-carbon multiple bonds and functionalized benzenes $[61,62]$.

Combining experimental and DFT studies, we reported the activity of metal-free carbon catalysts in the generation of $\mathrm{H}_{2}$ from formic acid [63]. In particular, we demonstrated that defects, especially single vacancies, are active in the formic acid dehydrogenation reaction even in the presence of oxygen groups, i.e., alcohols and carbonyls. Similar investigations including a wide range of carbon dopants proved the same results on ammonia reforming [64]. For the best of our knowledge, the decomposition of hydrazine on a metal-free carbon-based catalyst has been reported only on $\mathrm{g}-\mathrm{Si}_{3} \mathrm{C}$, which is able to adsorb $\mathrm{N}_{2} \mathrm{H}_{4}$ in its anti-configuration and decompose it following pathways different to those on metal surfaces [65].

In the present work, different carbonaceous materials, i.e., graphite and two different types of carbon nanofibers differing in graphitization degree (PR24-PS and PR24-HHT), were employed in the liquid phase hydrazine decomposition reaction. A systematic density functional theory (DFT) study on $\mathrm{N}_{2} \mathrm{H}_{4}$ adsorption and decomposition was employed to understand the role of the defects in this process, paving the pathway to the development of new and efficient carbo-catalysts.

\section{EXPERIMENTAL METHOD}

Materials and chemicals: CNFs PR24-PS and PR24-HHT were purchased from the Applied Science Company. These nanofibers were prepared with different post-treatment temperature, in order to remove polyaromatic carbon layers covering their external surface. The thermal treatments were performed at 700 and $3000{ }^{\circ} \mathrm{C}$ for PR24-PS and PR24-HHT, respectively. Graphite was obtained from Johnson Matthey. $\mathrm{N}_{2} \mathrm{H}_{4}$. $\mathrm{H}_{2} \mathrm{O}(98 \%)$, sodium hydroxide $(\mathrm{NaOH}, \geq 98 \%)$, hydrochloric acid $(\mathrm{HCl}, 37 \% \mathrm{wt})$ and 4dimethylaminobenzaldehyde (4-DMAB, $98 \%$ ) were acquired from Sigma-Aldrich.

Catalytic tests: Liquid phase $\mathrm{NH}_{2} \mathrm{NH}_{2} \cdot \mathrm{H}_{2} \mathrm{O}$ decomposition was performed at a constant reaction temperature of $50^{\circ} \mathrm{C}$ using a $50 \mathrm{~mL}$ three-necked round bottom flask, with one of the flask's neck connected with a burette employed for gas volume analyses.

Typically, the required amount of catalyst (hydrous hydrazine/catalyst weight ratio 15.7/1) was added in the reactor, where $16.0 \mathrm{~mL}$ of a $0.5 \mathrm{M} \mathrm{NaOH}$ aqueous solution was placed and heated at the desired temperature. Once the solution reached the desired temperature, $600 \mu \mathrm{L}$ of a $3.3 \mathrm{M}$ hydrous hydrazine aqueous solution was inserted and the final mixture was stirred at $1400 \mathrm{rpm}$ using a magnetic stirrer.

Product analyses: Hydrous hydrazine conversion was analysed using a Jasco V-730 Spectrophotometer, using a $1 \mathrm{~cm}$ quartz cell. The conversion was calculated according to the equation molin $-\mathrm{mol}_{\text {out }} /\left(\mathrm{mol}_{\text {in }} \times 100\right)$, 
where $\mathrm{mol}_{\text {in }}$ and molout are the initial and the remaining moles, respectively. The analytical method was based on the reaction of $\mathrm{N}_{2} \mathrm{H}_{4} \cdot \mathrm{H}_{2} \mathrm{O}$ with 4-dimethylaminobenzaldehyde (4-DMAB) in dilute hydrochloric acid (Scheme 1). The substrate quantitatively reacts with 4-DMAB to give a p-quinone structure that adsorb at $456 \mathrm{~nm}[66,67]$. The concentration was calculated using the Beer-Lambert equation.

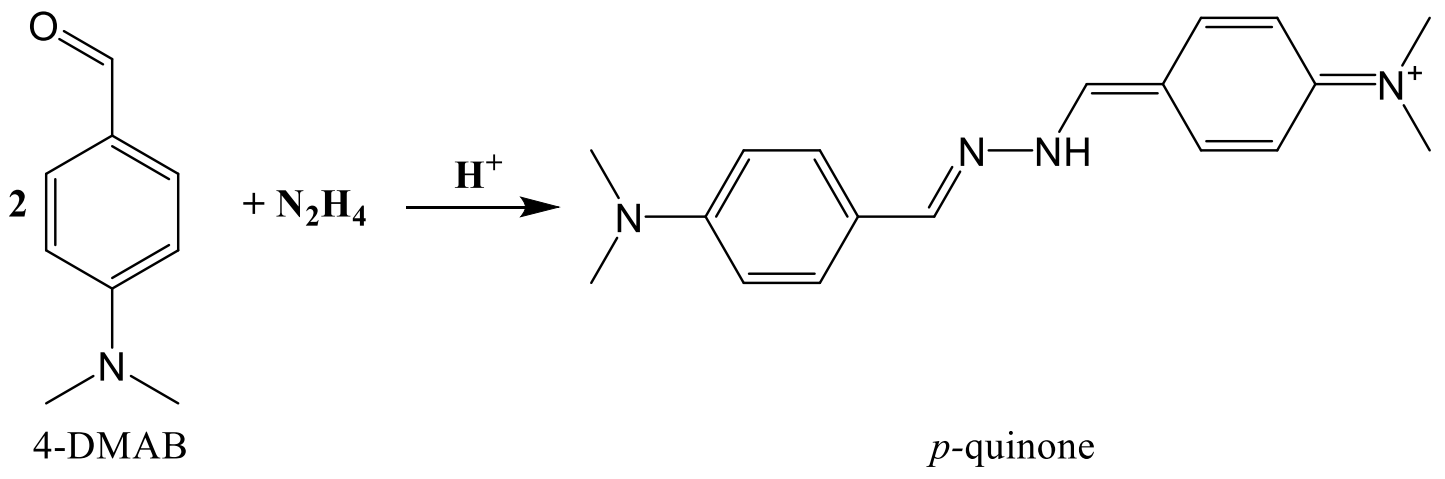

Scheme 1: Reaction of 4-DMAB and hydrazine to give the yellow p-quinone

The volume of gas produced was measured using the water displacement method. The gaseous products released were allowed to pass to a trap containing a $0.05 \mathrm{M} \mathrm{HCl}$ aqueous solution to ensure the removal of $\mathrm{NH}_{3}$, if any, and volumetrically monitored employing the burette. Using this method, the volume measured was only due to $\mathrm{N}_{2}$ and $\mathrm{H}_{2}$ molecules, enabling us to evaluate $n\left(\mathrm{~N}_{2}+\mathrm{H}_{2}\right)$. The selectivity to hydrogen $(x)$ was then calculated according to Eq. 5:

$3 \mathrm{NH}_{2} \mathrm{NH}_{2} \rightarrow(1+2 x) \mathrm{N}_{2}+6 x \mathrm{H}_{2}+4(1-x) \mathrm{NH}_{3}$

Considering the molar ratio $n\left(\mathrm{~N}_{2}+\mathrm{H}_{2}\right) / n\left(\mathrm{~N}_{2} \mathrm{H}_{4}\right)(\lambda), x$ can be evaluated as Eq. 6 :

$x=\frac{3 \lambda-1}{8}$

Catalyst characterization: Carbon samples were characterized by ICP-OES and Raman spectroscopy. Raman spectroscopy was executed using a Horiba LabRam HR Evolution micro-Raman spectrometer equipped with a green solid-state laser $(532 \mathrm{~nm})$ focused through a $100 \times$ objective, giving a spatial resolution of approximately $1 \mu \mathrm{m}$. The micro-Raman system was set with 300 lines per $\mathrm{mm}$ grating; the spectrum was collected with a final laser power of about $0.1 \mathrm{mWat}$. The sample surface was measured through a handheld power meter. Spectra were calibrated using the $520.7 \mathrm{~cm}-1$ line of a silicon wafer. The sample was scanned at an attenuation time of $300 \mathrm{~s}$ and 2 scans were performed giving a spectrum.

The presence of possible residual metal was analysed by inductively coupled plasma optical emission spectroscopy (ICP-OES) using a PerkinElmer Optima 8000 emission spectrometer.

Computational method: Periodic plane-wave density functional theory (DFT) calculations were carried out using the Vienna Ab-initio Simulation Package (VASP) [68,69]. The generalized gradient approximation from the revised Perdew-Burke-Ernzerhof approximation (RPBE) [70] has been used to take into account the correlation-exchange electronic contributions, with a kinetic energy cutoff of $500 \mathrm{eV}$ chosen for the expansion of the Kohn-Sham valence states plane-waves [71]. All the calculations includes the long-range dispersion correction approach by Grimme - DFT-D3 methods [72,73], an improvement on pure DFT to evaluate molecular interactions[74-77]. We also included the implicit solvation model as implemented in VASPsol $[78,79]$, where solvent is considered as a polarizable continuum dielectric bath. The optimization thresholds for electronic and ionic forces relaxation were respectively $10^{-5} \mathrm{eV}$ and $0.02 \mathrm{eV} / \AA ̊ \AA$. For Brillouin 
zone sampling, a 「-centered k-point mesh generated through Monkhorst-Pack method of dimensions $5 \times 5$ $\times 1$ in order to avoid Pulay stress [80]. To improve the convergence of the Brillouin-zone, a first order Methfessel-Paxton method has been used with an energetic width value of $0.2 \mathrm{eV}$. All carbon-based materials were modeled starting from a single layer slab of a $6 \times 6$ pristine graphene supercell and introduced different defects: single vacancy (SV), double vacancy (DV) and three different Stone Wales defects (SW1, SW2, SW3) [63]. The supercell is in a hexagonal crystalline system with unit cell vectors $a$ and $b$ lying in surface plane and perpendicular to $c$ axis. Both, $a$ and $b$, were optimized at $14.8 \AA$, in well agreement with experimental values obtained by Transmission Electron Aberration-corrected Microscope (TEAM) [81]. We introduced a polarizable continuum dielectric bath of $\sim 16 \AA$ perpendicular to the C-surface in order to avoid spurious periodic interactions with periodic images. Computational characterization of the surfaces was performed using the Bader analysis as implemented by Henkelmann et al. [82]. A fast convergence of charges with respect to the Fast Fourier Transform grid was obtained employing the Grid Method by Yu [83], which quadratically converges charge values with respect to mesh size. A grid of $370 \times 370 \times 390$ points was applied in order to optimize memory usage and precision of the calculations. These values were obtained converging two equivalent carbon charges in pristine graphene. Charge density local curvatures, local accumulations and depletions were evaluated to disclose the ability of every inequivalent surface site to adsorb and decompose hydrazine. The optimized parameters obtained from the Grid method were employed in a Laplacian topological analysis [84]. The AIM-UC Bader Analysis Toolkit implemented by David Vega et al. [85] was applied on a total electron density obtained combining the valence charge data and the core charges, resulting in Laplacian of charge density map, which allowed to analyze Bond Critical Points (BCP). Before adsorbing the hydrazine molecule, a systematic study on all possible active sites was performed using $\mathrm{NH}_{3}$ as a probe molecule and considering both dissociative and non-dissociative adsorption modes. The molecular adsorption energy $\left(E_{A D S}\right)$ was defined as the difference between the combined system and the isolated species. The reaction energy $\left(E_{R}\right)$ of each $\mathrm{N}_{2} \mathrm{H}_{4}$ dissociation elementary step was described as the total energy difference between the final (final adsorbate/C) and the initial states (initial adsorbate/C). Hydrogen diffusion calculations were performed on the single vacancy (SV) system, which proved to be the most active defect in this study. A hydrogen atom was placed in the desired position where only its $z$ coordinate could relax during the optimization calculation. Later on, all carbon atoms were allowed to relax except two of them sufficiently far from the active site to avoid rotations or translations of the considered surface as a whole [86]. The hydrogen diffusion energy $\left(E_{D}\right)$ was calculated as the energy difference between atomic hydrogen within the vacancy, in the most stable configuration, and diffused atomic hydrogen structures.

\section{$\underline{\text { RESULTS }}$}

Different carbonaceous materials, i.e., CNFs-PS, CNFs-HHT and graphite were employed as catalysts for the hydrous hydrazine reforming reaction. ICP-OES analysis was employed to ensure the absence of possible metallic impurities. The reaction conditions were optimized to assess the reaction kinetic regime and to establish the correct amount of catalyst to be used. The optimum conditions were at $50{ }^{\circ} \mathrm{C}$ and $1400 \mathrm{rpm}$, using $600 \mu \mathrm{L}$ of a hydrazine solution $3.3 \mathrm{M}$ in $16 \mathrm{~mL}$ of $\mathrm{NaOH} 0.5 \mathrm{M}$ and a $\mathrm{N}_{2} \mathrm{H}_{4} \cdot \mathrm{H}_{2} \mathrm{O}$ :catalyst weight ratio of 15.7:1. To ensure reproducibility, all the experiments were repeated three times. Figure 1 shows the different kinetic profiles for $6 \mathrm{~h}$ of reaction. CNFs-PS exhibited the highest conversion at $6 \mathrm{~h}(94 \%)$, whereas CNFs-HHT and graphite showed similar conversion ( $71 \%$ and $65 \%$, respectively) (Table 1, column 4 ). On the most active material, CNFs-PS, $\mathrm{H}_{2}$ selectivity was calculated using water displacement method and $89 \%$ selectivity for the complete hydrazine decomposition reaction was determined. 


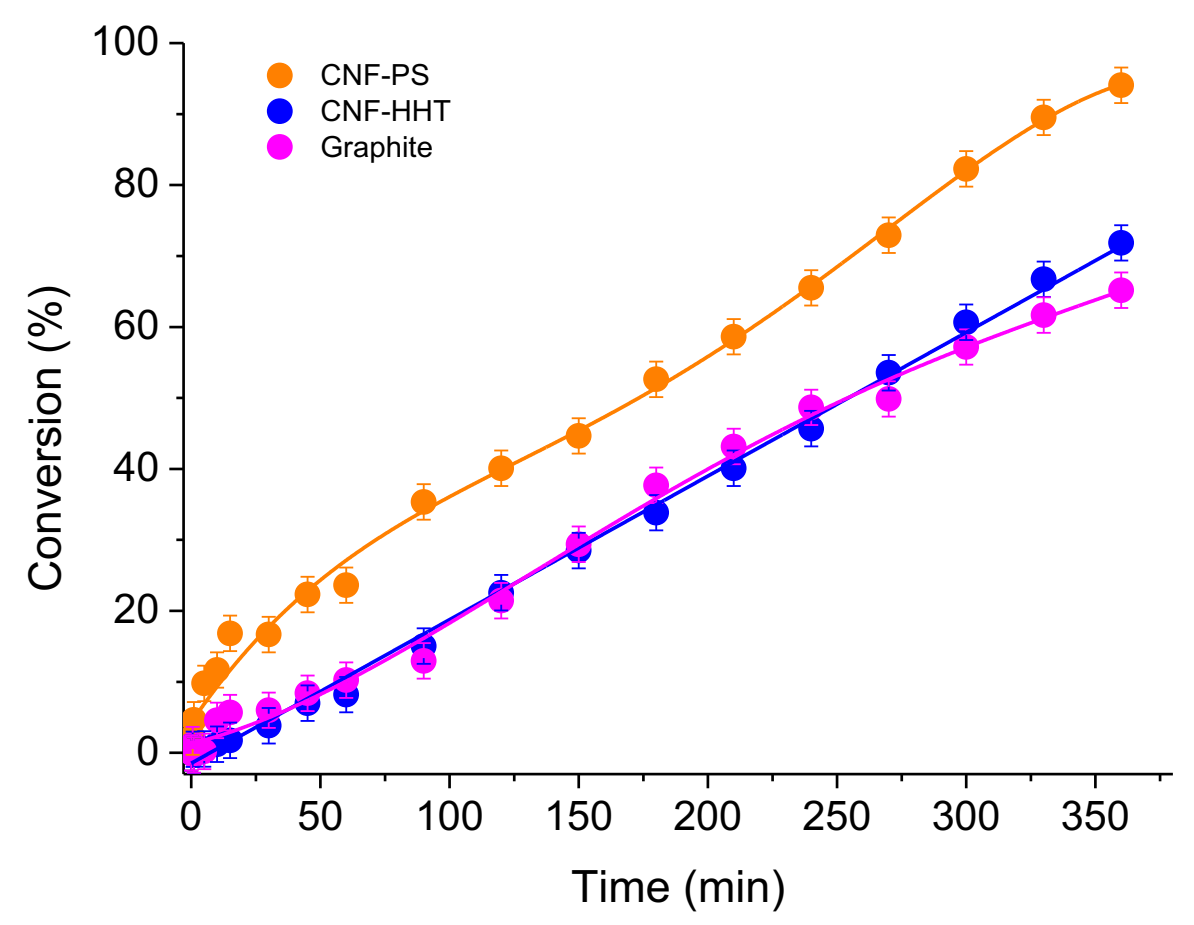

Figure 1 Conversion trend for the hydrazine decomposition reaction for the different carbonaceous materials: Graphite (violet), CNFs PR24-PS (orange) and PR24-HHT (blue). All the tests were performed at $50^{\circ} \mathrm{C}$ and $1400 \mathrm{rpm}$, using $600 \mu \mathrm{L}$ of a hydrazine solution 3.3 $\mathrm{M}$ in $16 \mathrm{~mL}$ of $\mathrm{NaOH} 0.5 \mathrm{M}$ and a $\mathrm{N}_{2} \mathrm{H}_{4} \cdot \mathrm{H}_{2} \mathrm{O}$ :catalyst weight ratio of 15.7:1.

In order to rationalize these results in terms of structural properties, we characterized all the catalysts using Raman spectroscopy. It allowed us to investigate the graphitization degree of carbon materials measuring the two bands at around $1600 \mathrm{~cm}^{-1}$ (G band) and $1350 \mathrm{~cm}^{-1}$ ( $D$ band) [87]. The $G$ band is generated by the $\mathrm{C}=\mathrm{C}$ stretching vibrations in the graphite lattice, and it is related to structurally ordered graphite domains. The $D$ band corresponds to the $A_{1 g}$ mode, which is forbidden according to the selection rules in graphite, but active in the presence of structural defects or in plane substitutional heteroatoms [87]. All carbon materials studied in this work present both $D$ and $G$ Raman bands with the following $I_{D} / I_{G}$ ratio: CNF-PS (1.54) > Graphite (0.20) > CNFs-HHT (0.11) (Figure S1 and Table 1).

Table 1: Raman characteristics of the carbon catalyst, their initial catalytic activity (15 minutes of reaction) and final conversion towards hydrazine decomposition (6 h).

\begin{tabular}{|l|l|l|l|}
\hline & Raman $\mathrm{I}_{\mathrm{D}} / \mathrm{I}_{\mathrm{G}}$ & $\begin{array}{l}\text { Activity at } 15 \mathrm{~min} \\
\left(\mathrm{mg}^{-1} \mathrm{~min}^{-1}\right) * 10^{2}\end{array}$ & $\begin{array}{l}\text { Conversion } \\
\text { at } 6 \mathrm{~h}(\%)\end{array}$ \\
\hline Graphite & 0.20 & 6.0 & 65 \\
\hline CNFs-PS & 1.54 & 18 & 94 \\
\hline CNFs-HHT & 0.11 & 1.9 & 71 \\
\hline
\end{tabular}

To unveil the effect of $\mathrm{NaOH}$ in the reaction environment, the most active material (i.e. CNFs-PS) was tested at the same experimental conditions, but with distilled water as solvent, i.e. $\mathrm{pH}=7$. From the comparison between the reaction profiles showed in Figure 2, it appears clear that the presence of $\mathrm{NaOH}$ affects not only the selectivity of the reaction, but also its kinetics $[11,46]$. Indeed, the catalyst tested at the same conditions with $\mathrm{NaOH}$ exhibited about $70 \%$ of hydrous hydrazine conversion at $4 \mathrm{~h}$ of reaction, while the same material tested in water presented a $15 \%$ conversion. 


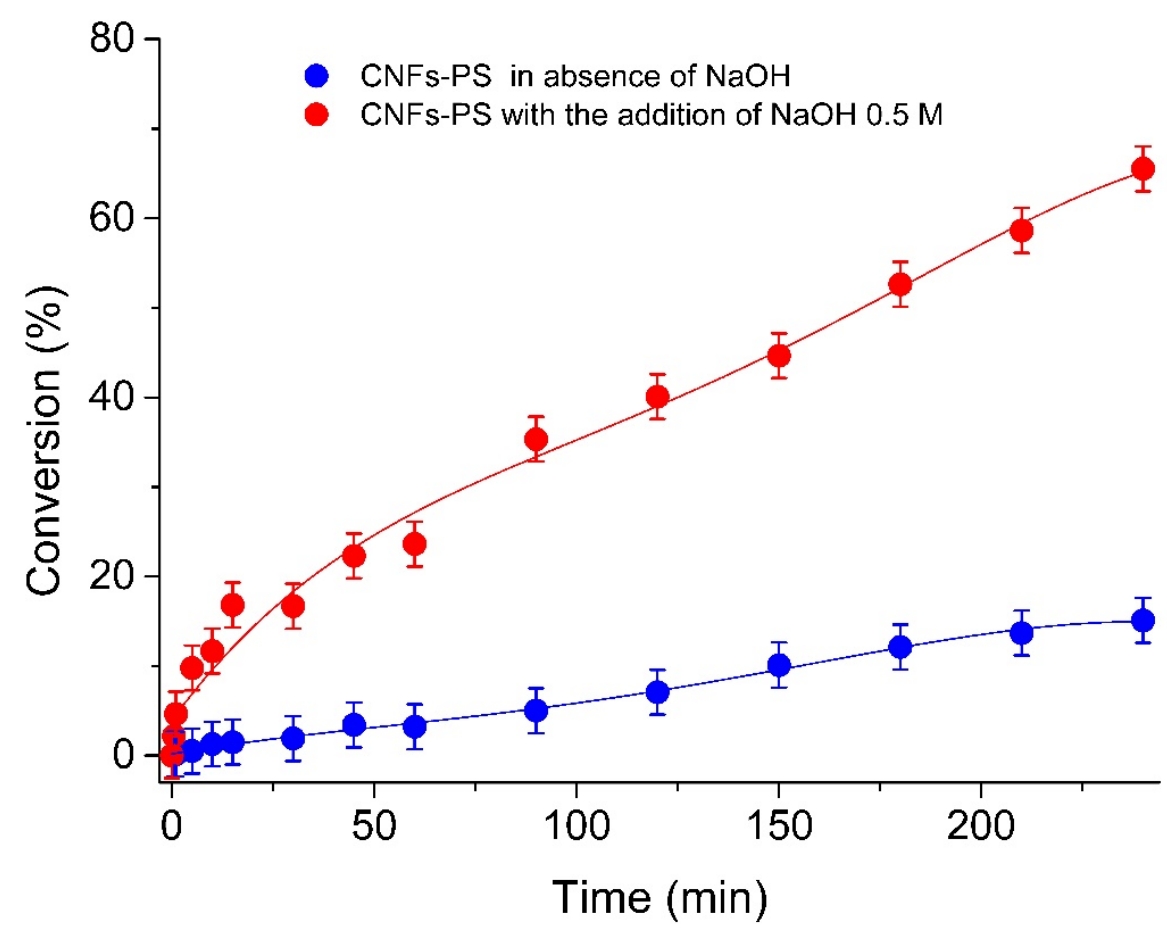

Figure 2 Comparison of conversion trend for hydrazine decomposition in a different reaction environment. Alkaline aqueous solvent, red solid line, and distilled water, blue solid line. All the tests were performed at $50^{\circ} \mathrm{C}$ and $1400 \mathrm{rpm}$, using $600 \mu \mathrm{L}$ of a hydrazine solution 3.3 $\mathrm{M}$ in $16 \mathrm{~mL}$ of solvent ( $\mathrm{NaOH} 0.5 \mathrm{M}$ for red profile, distilled water for the blue one) and a $\mathrm{N}_{2} \mathrm{H}_{4} \cdot \mathrm{H}_{2} \mathrm{O}$ :catalyst weight ratio of 15.7:1.

Systematic DFT simulations were performed to elucidate the roles of carbon defects in hydrazine activation and decomposition. Six different graphitic surfaces were modelled: pristine graphite (PG), single vacancy (SV), double vacancy (DV) and three different Stone-Wales defects (SW, VSW1, VSW2), represented in Figure S1. Prior to proceed with the adsorptions, we performed an evaluation of charge density at Bond Critical Points (BCP)[88] to estimate the potential active sites of the different optimized surfaces (Figure S1). As previously shown, only sites presenting distortions in the graphene $\pi$-system are able to interact favourably with adsorbates [64]. The obtained electron densities measured on the defects are summarised in Table 2. It was observed that only SV and DV are potential catalysts candidates to bind $\mathrm{N}_{2} \mathrm{H}_{4}$ as these two structures contain dangling C-atoms lacking electron density [63]. This result, underling the localization of the catalytic site on both SV and DV.

Table 2: Charge density at Bond Critical Points of the potential active sites.

\begin{tabular}{c|c}
$\begin{array}{c}\text { Surface } \\
\text { Site }\end{array}$ & $\rho\left(\vec{r}_{B C P}\right) / \frac{e^{-}}{\AA^{3}}$ \\
\hline \hline PG & 2.03 \\
\hline SV & 0.587 \\
\hline DV & 0.974 and 0.979 \\
\hline SW & $1.863-2.589$ \\
\hline
\end{tabular}




\begin{tabular}{c|c}
\hline VSW1 & $1.628-2.156$ \\
\hline VSW2 & $1.602-2.134$
\end{tabular}

We validated the assumptions regarding the active sites by using ammonia $\left(\mathrm{NH}_{3}\right)$ as a probe molecule. It was brought near non-equivalent active sites and the system relaxed. In line with previous studies, the graphitic areas possess an inactive $\pi$-conjugation, not sensitive to adsorption of molecules [64,89-91]. Only single vacancies showed a favourable (exothermic) interaction with ammonia, indicating that a $\rho\left(\vec{r}_{B C P}\right)$ smaller than $0.6 \frac{e^{-}}{\AA^{3}}$ defines the active sites on carbon surfaces. Combining the Laplacian of charge density analysis and the performed tests with $\mathrm{NH}_{3}$, we were able to identify $\mathrm{C}_{3}, \mathrm{C}_{3^{\prime}}$ and $\mathrm{C}_{7}$ in the single vacancy system as possible active sites (Figure 3 ). Then, hydrazine was placed and relaxed on such sites with different initial orientations. We also investigated the molecule dissociative adsorption [92,93], i.e., breaking the $\mathrm{N}-\mathrm{H}$ or $\mathrm{N}$ $\mathrm{N}$ bonds while forming a new one with the surface similar to previous works on metal surfaces.
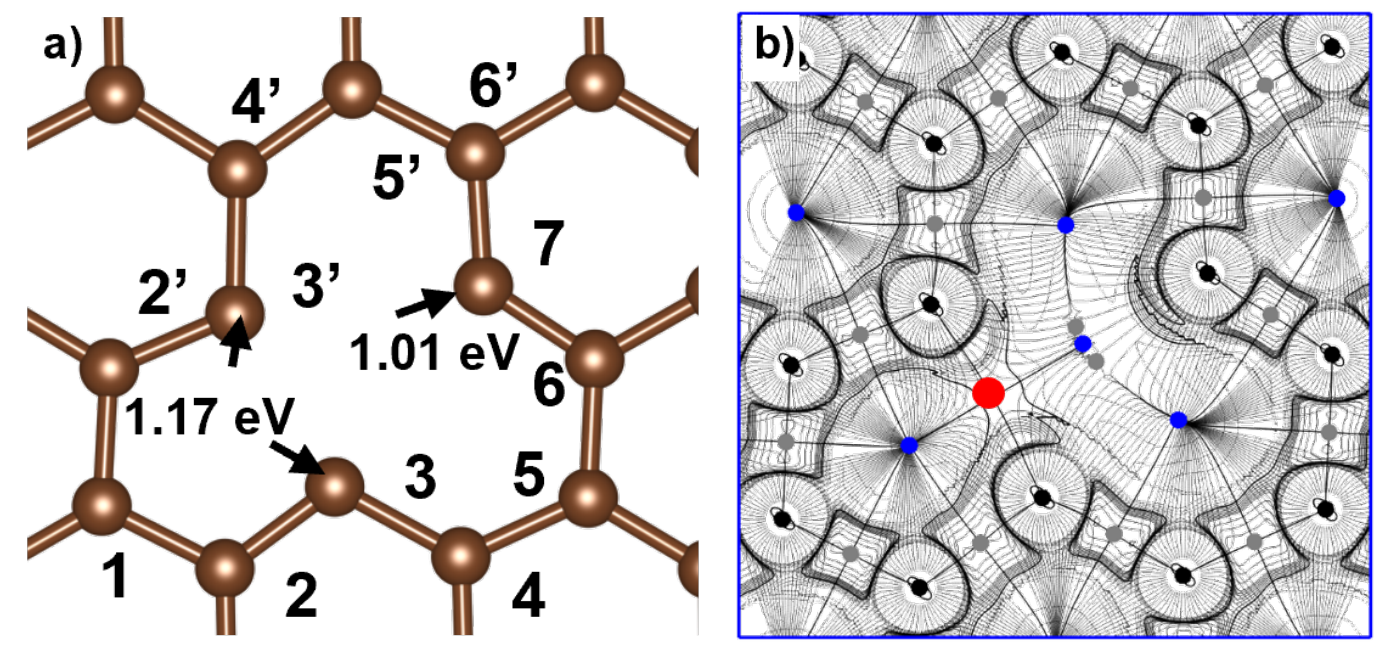

Figure 3 Single vacancy representation. a) Individuated active sites and $\mathrm{NH}_{3}$ relative adsorption energies. b) Charge-density Laplacian analysis iso-surfaces plot; Red circle indicates the evaluation site for $\rho\left(\vec{r}_{B C P}\right)$, black circles indicate nuclear charge density maxima, grey Bond Critical Points and blue Ring Critical Points.

The least stable $\mathrm{N}_{2} \mathrm{H}_{4}$ adsorption configuration is the anti-single linked ( $a$-SL) configuration where hydrazine bonded $\mathrm{C}_{3}$ (Figure 4a). When the molecule is bonded to two active sites in a bridge configuration, it may adopts the cis-bridged $(c B-N)$ configuration driving the $\mathrm{N}-\mathrm{H}$ dissociation (Figure $4 \mathrm{~b}$ ) or the cis-bridged $(c B-H)$ structure resulting in the $\mathrm{N}-\mathrm{N}$ bond scission (Figure $4 \mathrm{c}$ ). It can be seen from the adsorption energies inserted in Figure 4 that the resulting stability increases following the sequence a-SL $<\mathrm{cB}-\mathrm{N}<\mathrm{cB}-\mathrm{H}$. Zheng et al. investigated the same adsorption process on metal-free $\mathrm{SiC}_{3}$ siligraphene resulting in the following stability sequence: cis- $\mathrm{N}_{2} \mathrm{H}_{4}<$ gauche- $\mathrm{N}_{2} \mathrm{H}_{4}<$ anti- $\mathrm{N}_{2} \mathrm{H}_{4}$ [65]. In addition, mechanistic studies performed on metal surfaces, such as Ir [94], $\mathrm{Cu}$ [95], $\mathrm{Ni}$ [96-98] and Pt [99], are consistent with the siligraphene trends. In our study, a gauche adsorbed configuration was not obtained from structural optimizations, which shows $\mathrm{C}$ behaves differently to $\mathrm{SiC}_{3}$ siligraphene and metals. Unlike in these studies, the different adsorption modes on defective graphene are driven by the lack of electron density. Hence, the $a$-SL structure only saturates one dangling carbon atom showing a week adsorption energy $\left(E_{A D S}=-0.78 \mathrm{eV}\right)$, whereas when two or more 
dangling bonds are saturated ( $\mathrm{CB}-\mathrm{N}$ and $\mathrm{CB}-\mathrm{H}$, respectively), the species are more strongly bonded to the surface.

$E_{A D S}=-0.78 \mathrm{eV}$

a)
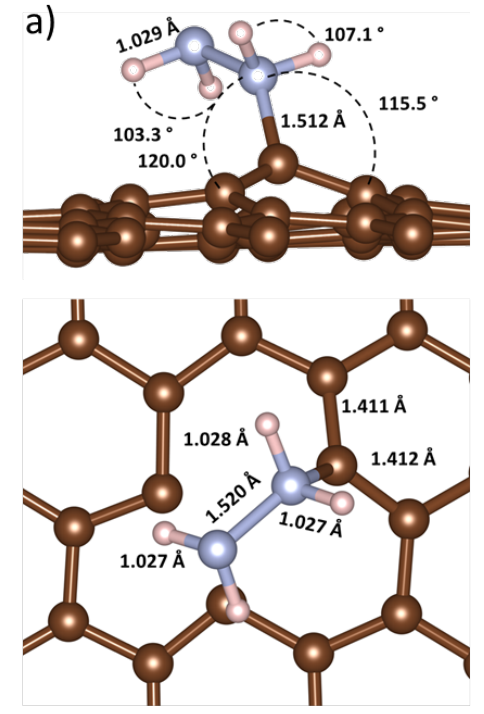

$E_{A D S}=-3.00 \mathrm{eV}$
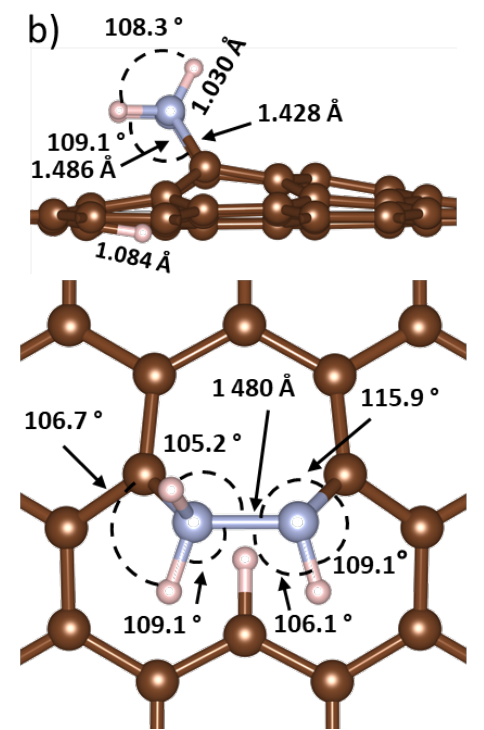

c)
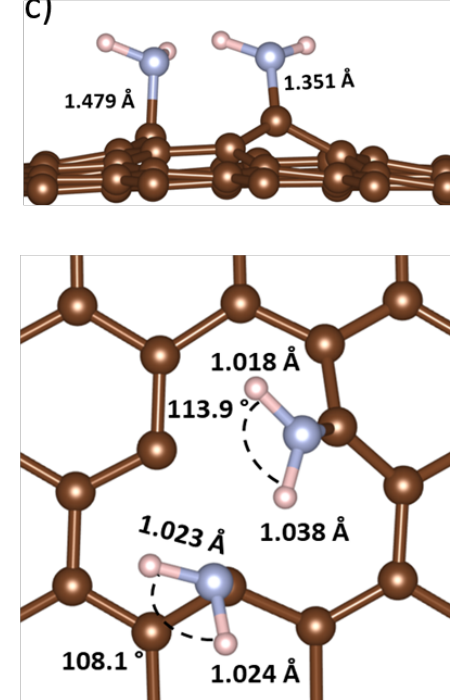

Figure 4: Top and side view of the most favourable Hydrazine configurations: a) a-SL b) $C B-N C)(B-H$. Inset are the adsorption energies $\left(E_{A D S}\right)$ and the main distances $(\AA)$ and angles $\left({ }^{\circ}\right)$ of interest. Carbon atom is labelled in brown, nitrogen in blue and hydrogen in white.

We considered two symmetric and one asymmetric dehydrogenations, and incomplete decomposition pathways based on previous reports [19-21]. However, only the most stable routes to the formation of $\mathrm{H}_{2}$ and $\mathrm{NH}_{3}$ was analysed in detail. The $\mathrm{CB}-\mathrm{H}$ was the most stable adsorption configuration and the first step for the complete hydrazine reforming (Eq. 1), whereas the $C B-N$ was the first step towards an incomplete hydrazine decomposition (Eq. 2) (Figure $4 b$ and c). The difference in energy between the $\mathrm{N}-\mathrm{H}$ and the N-N dissociative adsorptions indicated that the hydrogen production pathway was the preferable one ( $\triangle \mathrm{E}$ (NN-NH) $=0.450 \mathrm{eV}$ ). Indeed, once the $\mathrm{N}-\mathrm{H}$ bond was broken and a $\mathrm{C}_{3}-\mathrm{H}$ was formed leading towards the hydrogen production.

To proceed with dehydrogenation reaction mechanisms, we could consider a negligible activation energy for the migration of the dissociated $\mathrm{H}$ adatoms similar to the spill on metal catalysts [100]. However, the SV is a point defect, and the active site is isolated from adjacent dangling bonds. Thus, two different hydrogen production pathways were tested (Figure 5). The first one, SWC-Decomposition (Symmetric non-directional solvent Complete decomposition, Figure 5), simulated the absence of an alkaline aqueous medium and the $\mathrm{H}$ species needed to overcome a non-negligible diffusion energy barrier to free the active site. Hence, we investigated the $\mathrm{H}$ migration along three different paths (Figure S3) in similar fashion to previous studies [101-103]. For the most favourable migration pathway (Figure S4), we obtained a diffusion energy barrier of $\left(E_{D}\right) 3.48 \mathrm{eV}$ in polarizable continuum background, which did not provide a realistic directional solvation in aqueous solutions [102] (Figure S5). According to our simulations, two $\mathrm{H}$ atoms occupying nearest neighbour dangling carbon sites had an endothermic reaction energy $\left(E_{R}=2.90 \mathrm{eV}\right)$ to form $\mathrm{H}_{2}$ (Figure S6). However, the experiments were performed in solution, which surrounded $\mathrm{H}^{*}$ with an arranged (dipole) solvation shell promoting the $\mathrm{H}$ diffusion through the solution as well as the $\mathrm{H}_{2}$ evolution through the Heyrovsky mechanism [104]. Thus, we considered the desorption from $C_{3}$ (Figure 3) negligible in comparison with the energy 
required to dissociate and form $\mathrm{N}-\mathrm{H}$ and $\mathrm{N}-\mathrm{N}$ bonds. The second mechanism tested for the release of $\mathrm{C}_{3}, \mathrm{SAC}-$ Decomposition (Symmetric Alkaline Complete decomposition, Figure 5), did not involve diffusion and recombination but the formation of water with the $\mathrm{OH}^{-}$groups. Indeed, sodium hydroxide could interact and promote the reactivation of the $\mathrm{C}$ site to proceed with the dehydrogenation steps.

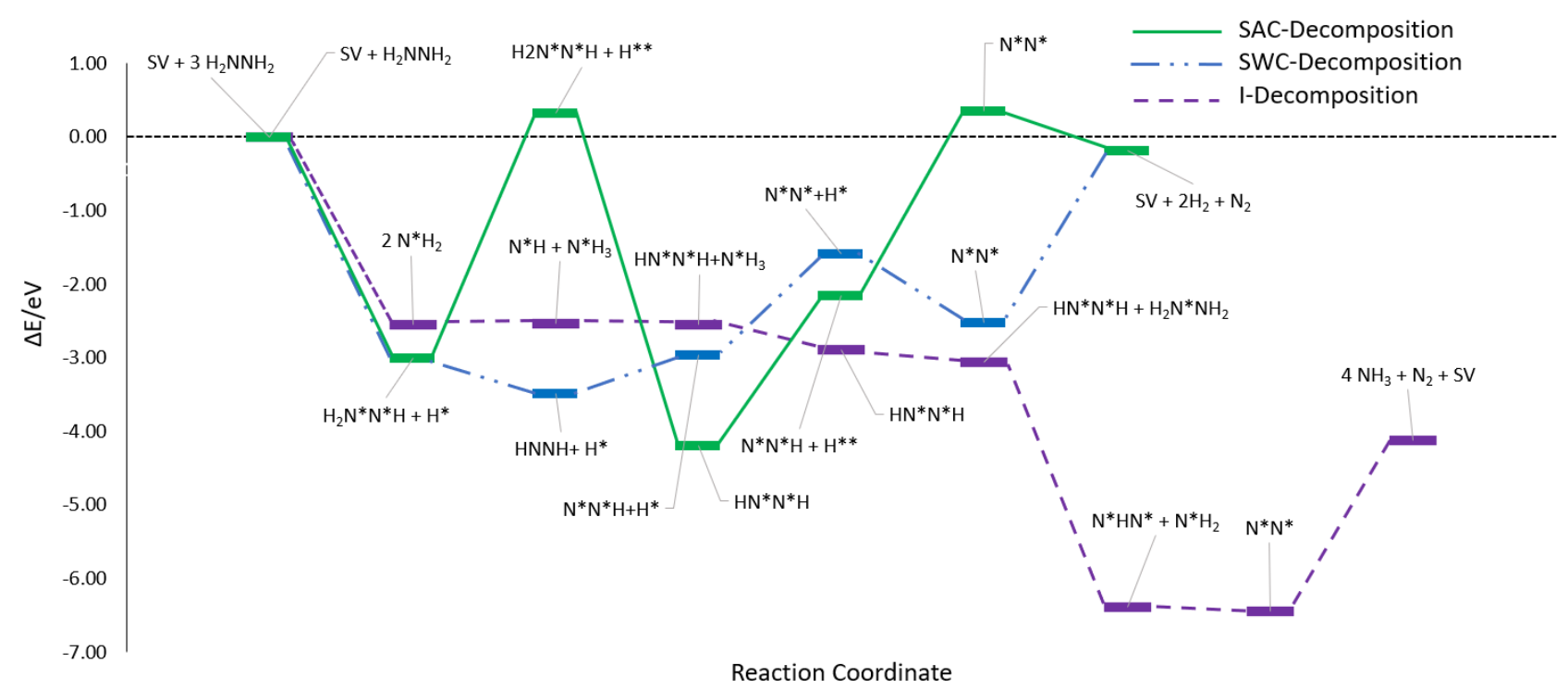

Figure 5 Energy profiles for hydrazine decomposition pathways. Purple line indicates the incomplete decomposition pathway leading to $\mathrm{NH}_{3}$ (I-decomposition), blue and green lines indicate the two possibilities of symmetric dehydrogenation with $\mathrm{NaOH}$ and water (respectively SWC- and SAC- decomposition. In the SWC-Decomposition pathway $H^{* *}$ indicates diffused atomic hydrogen species, a single * is used to indicate which atom is adsorbed on surface active sites.

\section{SWC $\mathrm{H}_{2}$ production}

The first dehydrogenation on $\mathrm{CB}-\mathrm{H}$ structure, common to both SAC and SWC pathways, presented an increment in the $\mathrm{N}$ centres $\mathrm{sp}^{3}$ character and the $\mathrm{N}-\mathrm{N}$ bond stretches by about $0.03 \AA$, while the $\mathrm{N}-\mathrm{H}$ stretching was negligible. The $\mathrm{C}_{3}-\mathrm{N}$ and $\mathrm{C}_{7}-\mathrm{N}$ bonds equilibrium lengths were not symmetric and differed by $0.058 \AA$. In addition, the initial SV site changed its structure to accommodate the adsorbed species (Figure 6a and Error! Reference source not found.a). In the following step along the SWC pathway, the adsorbed $\mathrm{H}_{2} \mathrm{~N}^{*} \mathrm{~N}^{*} \mathrm{H}$ intermediate may take three different dehydrogenation pathways: two symmetric and one asymmetric (Figure 5). Among all symmetric decomposition pathways, SWC was the most favourable one, and for this reason, it will be the only one considered (Figure 5, SWC-decomposition). Upon diffusion on the co-adsorbed $\mathrm{H}$ (Figure $6 \mathrm{~b}, \mathrm{E}_{\mathrm{R}}=3.319 \mathrm{eV}$, the intermediate HNNH (Figure 6c) showed a N-N bond contraction of $0.037 \AA$ and a reduction of the $\mathrm{C}_{3}-\mathrm{N}$ and $\mathrm{C}_{7}-\mathrm{N}$ bond lengths ( $0.094 \AA$ and $0.005 \AA$, respectively). The superior stability of the adsorbed $\mathrm{HN}^{*} \mathrm{~N} * \mathrm{H}$ compared to the asymmetric counterpart, $\mathrm{H}_{2} \mathrm{~N}^{*} \mathrm{~N}^{*}(\Delta \mathrm{E}$ Asymm-symm $=0.739 \mathrm{eV}$ ) could be related to the higher symmetry of the structure. The energy needed to overcome the $\mathrm{H}_{2}$ in-vacancy recombination energy leaded to an endothermic step $\left(E_{R}=1.066 \mathrm{eV}\right)$. The subsequent step proceeded through the scission of another $\mathrm{N}-\mathrm{H}$ bond (Figure $6 \mathrm{~d}$ ). The dehydrogenated $\mathrm{N}$ centre assumeed a $\mathrm{sp}^{2}$ hybridization, i.e., planar configuration. The structure obtained was exceptionally exothermic due to an overall dangling carbons saturation $\left(E_{R}\right.$ of $\left.-3.625 \mathrm{eV}\right)$. Nonetheless, the contribution of $E_{D}(+3.48 \mathrm{eV})$ slightly increaseed the reaction energy. In the final structure (Figure $6 \mathrm{e}, \mathrm{E}_{\mathrm{R}}=+2.50 \mathrm{eV}$ ), N-N bond showed an additional contraction indicating an increasing sp hybridization, typical of molecular $\mathrm{N}_{2}$, which spontaneously evolveed from the surface freeing the active site $\left(E_{R}=-0.19 \mathrm{eV}\right)$. 

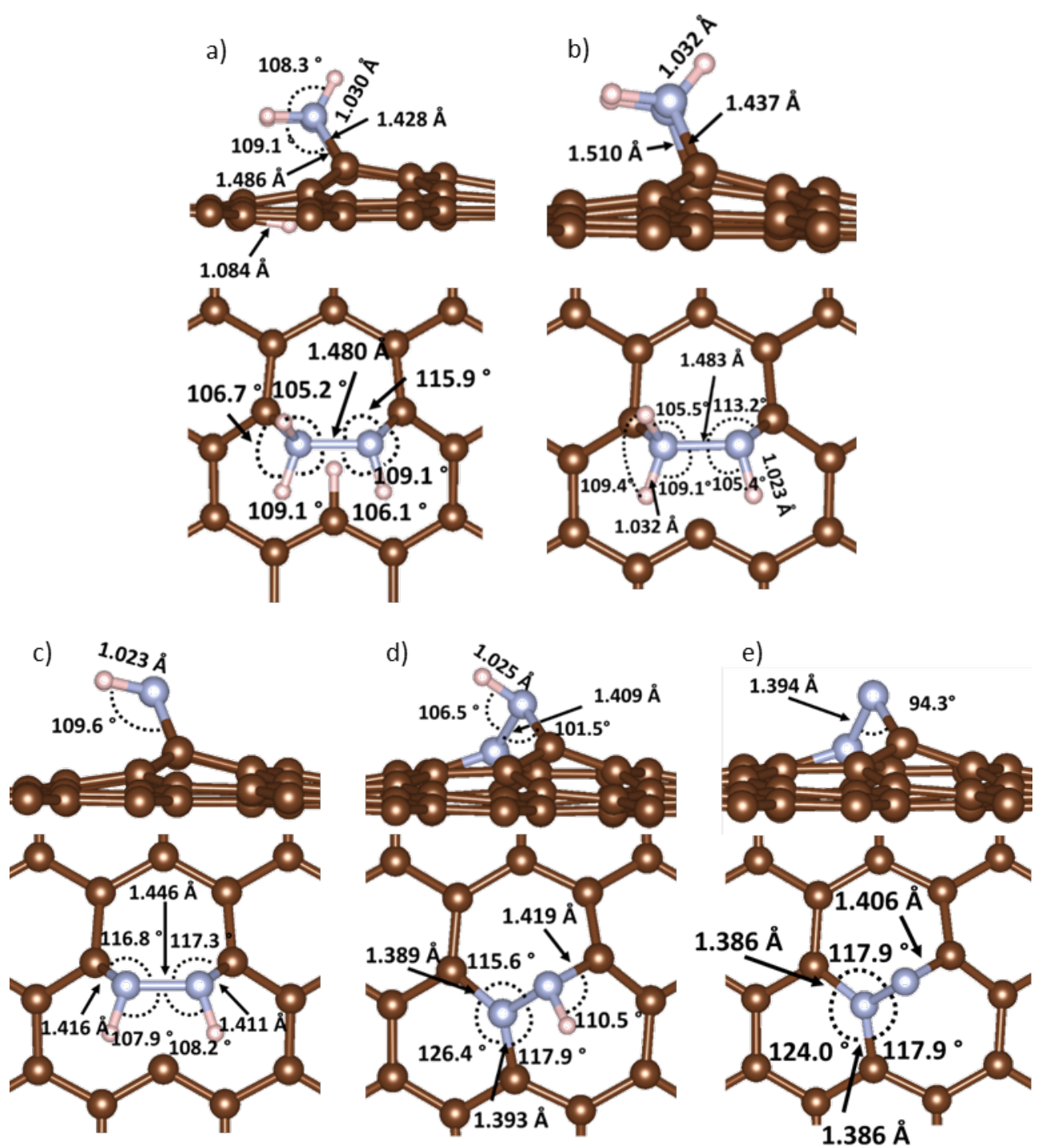

Figure 6: Top and side view of the most favourable hydrazine configurations for $\mathrm{H}_{2}$ production in water: a) Dissociative adsorption step $\mathrm{N}^{*} \mathrm{H}_{2} \mathrm{~N}^{*} \mathrm{H}+\mathrm{H}^{*}$, b) Hydrogen diffusion step $\mathrm{N}^{*} \mathrm{H}_{2} \mathrm{~N}^{*} \mathrm{H}+\mathrm{H}^{* *}, c$ ) second dehydrogenation step and $\mathrm{H}_{2}$ evolution, $\mathrm{N}^{*} \mathrm{HN} * \mathrm{H}, d$ ) third dehydrogenation step with diffusion, $\mathrm{N}^{*} \mathrm{~N}^{*} \mathrm{H}+\mathrm{H}^{* *}$ and e) last dehydrogenation step, $\mathrm{H}_{2}$ and $\mathrm{N}_{2}$ evolution, $\mathrm{N}^{*} \mathrm{~N}^{*}$. Inset, distances $(\AA)$ and angles $\left({ }^{\circ}\right)$ of interest. Carbon atoms are labelled in brown, nitrogen in blue and hydrogen in white.

\section{SAC H2 production}

The presence of $\mathrm{NaOH}$ as alkaline medium (SAC) leaded to a more favourable dehydrogenation pathway (Figure 5). Error! Reference source not found. shows the SAC-Decomposition mechanism where, in each step, the dangling bonds were completely saturated increasing its stability. The dissociative adsorption step (Figure 7a) was followed by a further hydrogen extraction (Error! Reference source not found.b, $E_{R}=-0.491$ eV) due to the interaction with $\mathrm{OH}^{-}$ions, which presented an exothermic behaviour. Differently from the $\mathrm{SWC}$, the formation of a $\mathrm{C}_{3}-\mathrm{H}$ bond influenced both structures and energies $(\Delta \mathrm{E}$ swc-sAC $=3.810 \mathrm{eV}$, Figure $6 \mathrm{~b}$ and Error! Reference source not found.b). The N-H and C-N bonds were more contracted, in particular the C-N bonds respectively by 0.018 and $0.045 \AA$, while the $\mathrm{N}-\mathrm{H}$ bonds by 0.004 and $0.013 \AA$. In the subsequent step (Error! Reference source not found.c, $E_{R}=0.525 \mathrm{eV}$ ), further dehydrogenation was performed with the in-situ evolution of a molecular hydrogen specie. The $\mathrm{C}-\mathrm{N}$ bond related to the bare $\mathrm{N}$ centre contracted by $0.085 \AA$, while either $\mathrm{N}-\mathrm{N}$ or $\mathrm{N}-\mathrm{H}$ bonds did not show any variation. Moreover, it is possible to observe that the bare $\mathrm{N}$ centre tilted towards the $\mathrm{C}_{3}-\mathrm{H}$. Overall, the step is slightly endothermic, due to the breakage of the $\mathrm{N}-\mathrm{H}$ bond. Subsequently (Error! Reference source not found.d), the bare $\mathrm{N}$ centre bonded to $\mathrm{C}_{3}$ and a scission of the $\mathrm{N}-\mathrm{H}$ bond occurred and the atomic $\mathrm{H}$ bonded to a non-active $\mathrm{C}$ atom $\left(\mathrm{E}_{\mathrm{R}}=+1.377 \mathrm{eV}\right)$. Indeed, 
from Error! Reference source not found.d it is possible to observe that the structure was deformed in order to bond the $\mathrm{H}$ atoms. The structure of the last dehydrogenation step (Error! Reference source not found.e) was completely equivalent to the one described in the SWC mechanism (Figure 6e). Nonetheless, from the energetic point view, the difference was mainly related to $\mathrm{H}_{2}$ evolution. Indeed, in the SWC mechanism it was necessary to overcome the energetic barrier deriving from the in-vacancy recombination of two diffused $\mathrm{H}$ atoms $\left(E_{R}=2.900 \mathrm{eV}\right.$, Figure $\left.\mathrm{S} 6\right)$. Here, the hydrogen evolution did not require any recombination, leading to an exothermic step $\left(E_{R}=-0.937 \mathrm{eV}\right)$. In the last step, $N_{2}$ evolution was endothermic and required overcoming an energetic barrier of $2.328 \mathrm{eV}$.

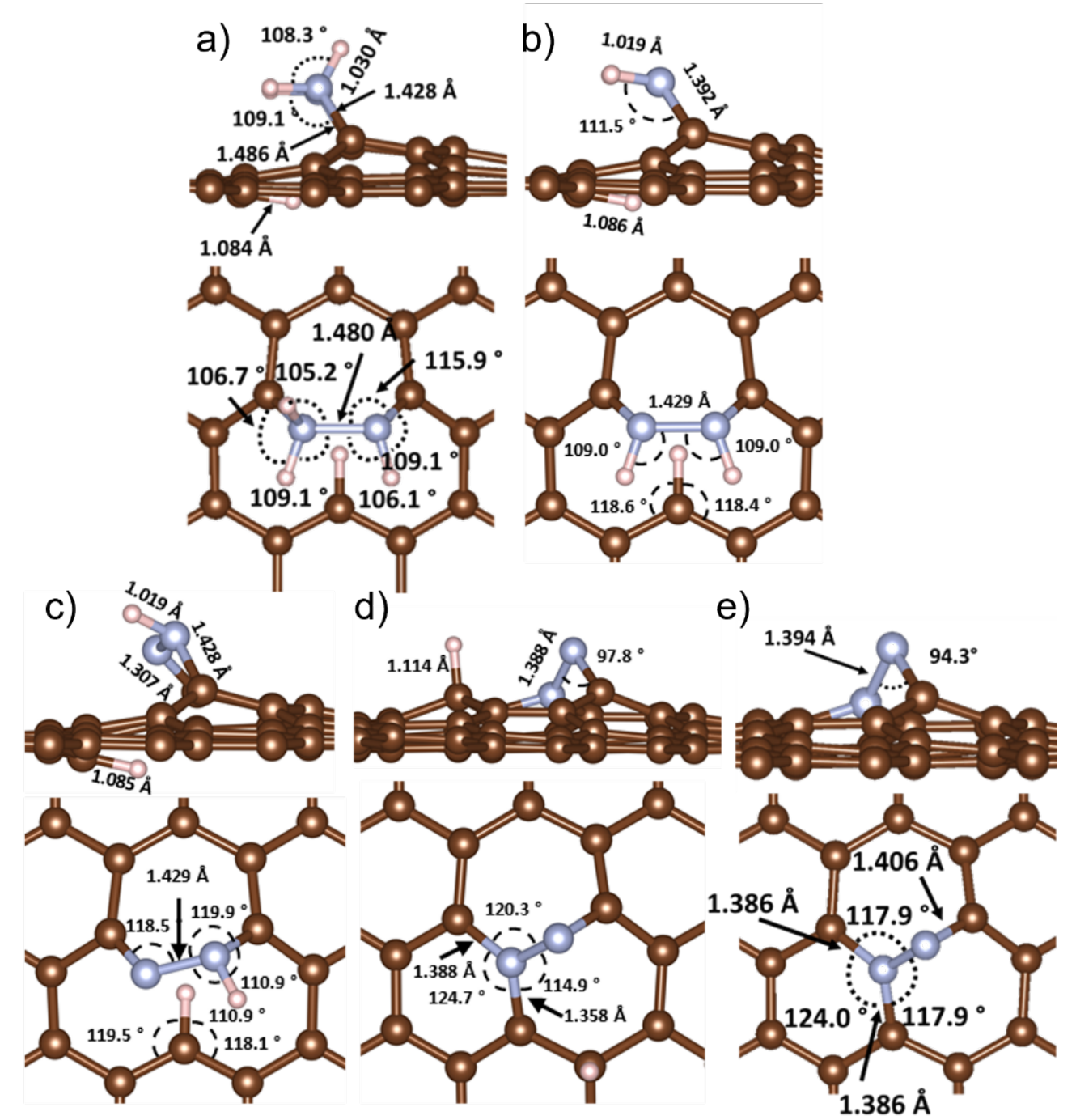

Figure 7 Top and side view of the most favourable hydrazine configurations for $\mathrm{H} 2$ production in presence of aqueous $\mathrm{NaOH}$ : a) Dissociative adsorption step $N^{*} H 2 N^{*} H+H^{*}$, b) Dehydrogenation step: $N^{*} H N^{*} H+H^{*}$, c) second dehydrogenation step and $H 2$ evolution, $N^{*} N^{*} H+H^{*}$, d) third dehydrogenation step, $N^{*} N^{*}+H^{*}$ and e) last dehydrogenation step, $H 2$ and $N 2$ evolution, $N^{*} N^{*}$. Inset, distances $(A)$ and angles $\left({ }^{\circ}\right)$ of interest. Carbon atoms are labelled in brown, nitrogen in blue and hydrogen in white.

\section{$\mathrm{NH}_{3}$ production}

The first step of $\mathrm{NH}_{3}$ production (Figure 8a) involved the breakage of $\mathrm{N}-\mathrm{N}$ bond upon adsorption, forming the $c B-N$ structure $\left(E_{A D S}=-2.55 \mathrm{eV}\right)$. The two adsorbed $\mathrm{NH}_{2}$ lied on the dangling carbons with $\mathrm{sp}^{3}$-like configuration. The following elementary step consisted in a hydrogen transfer, involving the two $\mathrm{N}^{*} \mathrm{H}_{2}$, followed by the $\mathrm{NH}_{3}$ evolution. As can be seen from the structure in Figure $6 \mathrm{~b}$, the remaining $\mathrm{N}^{*} \mathrm{H}$ tilted toward vacancy centre. A contraction of the free dangling carbons $\left(C_{3}-C_{3^{\prime}}\right)$ distance is then observed, leading to a slightly endothermic process $\left(E_{R}=+0.018 \mathrm{eV}\right)$. To close the catalytic cycle, a subsequent hydrazine 
adsorption bridging between the available active sites was considered (Figure $6 \mathrm{c}$ ). The initial $\mathrm{N}^{*} \mathrm{H}$ took two hydrogen atoms from the second $\mathrm{N}_{2} \mathrm{H}_{4}$ in a concerted mechanism upon its adsorption, leading to the formation of $\mathrm{HN}^{*} \mathrm{~N} * \mathrm{H}+\mathrm{N}^{*} \mathrm{H}_{3}$. This step showed an overall exothermic energy $\left(\mathrm{E}_{\mathrm{R}}=-0.019 \mathrm{eV}\right)$, along with the following $\mathrm{NH}_{3}$ exothermic evolution process, leading $\mathrm{HN}^{*} \mathrm{~N}^{*} \mathrm{H}$ on the SV (Figure $6 \mathrm{~d}, \mathrm{E}_{\mathrm{R}}=-0.35 \mathrm{eV}$ ). In the subsequent elementary step, a third hydrazine could exothermically co-adsorb on the under-coordinated carbon sites $C_{7}\left(E_{R}=-0.163 \mathrm{eV}\right.$, Figure 8e). In this position, the third hydrazine molecule interacted with an $\mathrm{H}$ of the adsorbed $\mathrm{HN}^{*} \mathrm{~N}^{*} \mathrm{H}$ yielding a $\mathrm{NH}_{3}$ molecule (Figure 8e). The structure obtained is energetically favourable $\left(E_{R}=-3.33 \mathrm{eV}\right.$, Figure $\left.8 \mathrm{f}\right)$ and the $\mathrm{H}$-free $\mathrm{N}$ bridged between two carbon sites with a $\mathrm{sp}^{2}$ hybridization. Instead, the $\mathrm{C}_{7}$ atom was saturated connecting two $\mathrm{N}$ atom, showing a conventional $\mathrm{sp}^{3}$ geometry. The interaction between $\mathrm{N}^{*} \mathrm{H}_{2}$ and the $\mathrm{H}$ located on the bridged $\mathrm{HN}^{*} \mathrm{~N}^{*}$ leaded to the evolution of the last $\mathrm{NH}_{3}$ (Figure $8 f, E_{R}=-0.05 \mathrm{eV}$ ). The resulting $\mathrm{N}_{2}$ was anchored on the carbon lattice $\left(E_{R}=+2.32 \mathrm{eV}\right)$ analogously to the SAC hydrogen production pathway. 

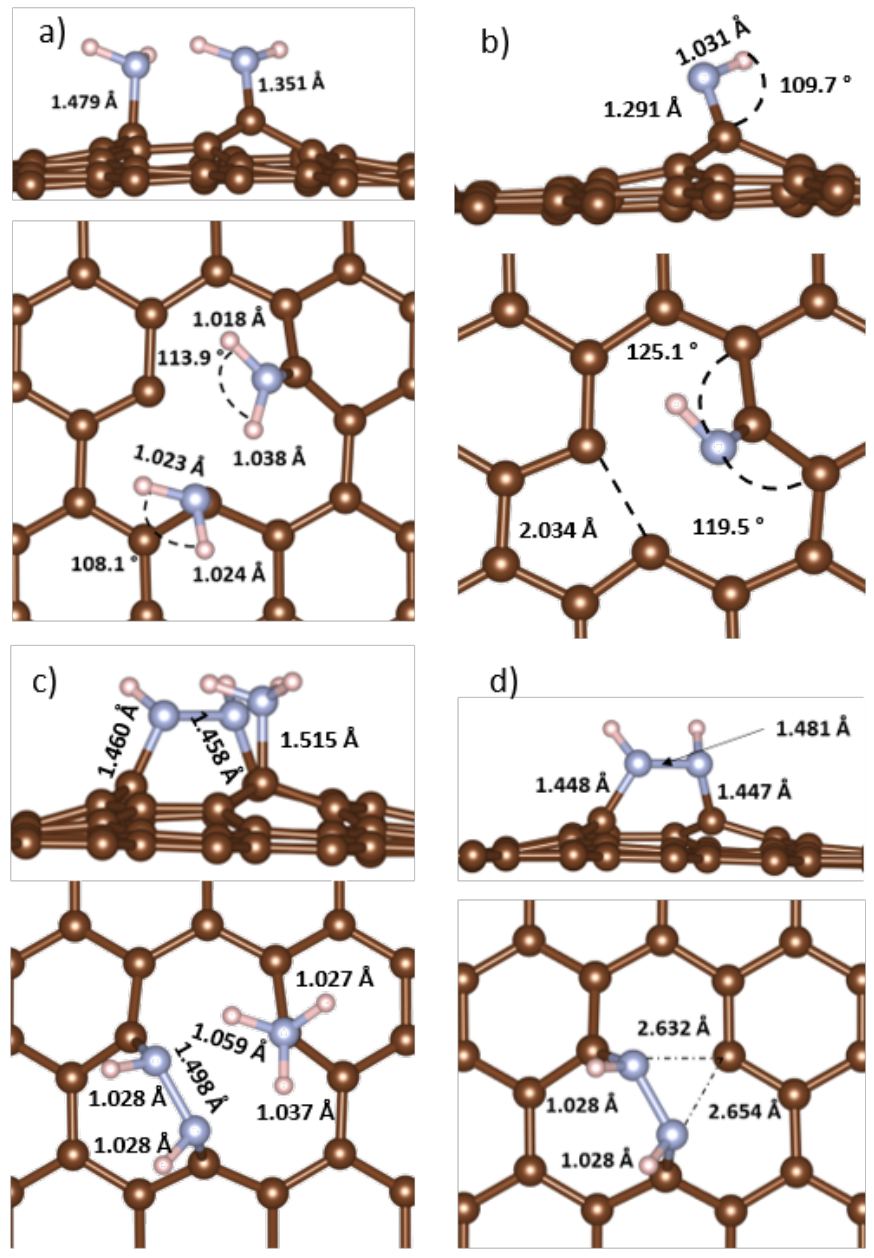

d)
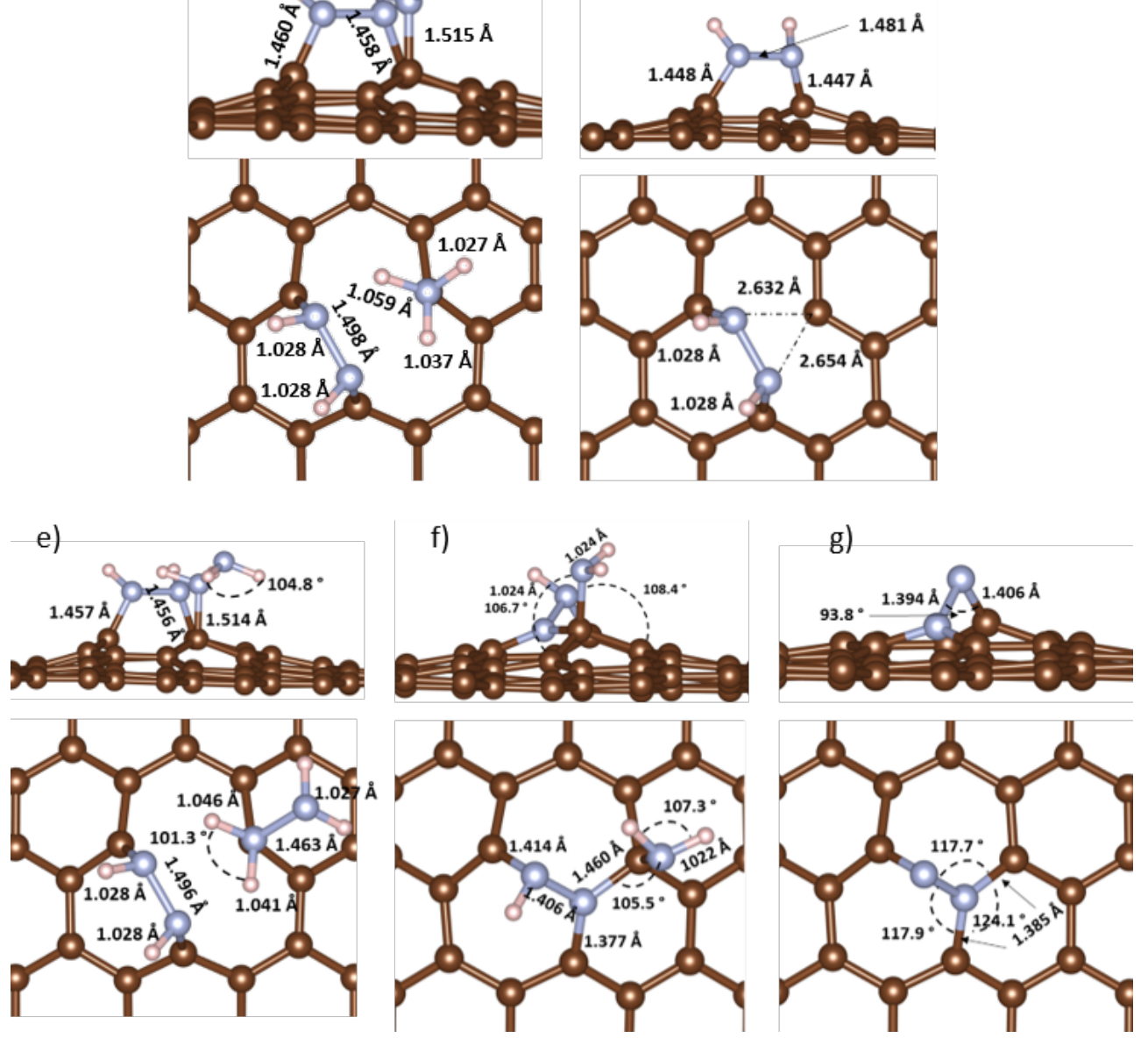

Figure 8 Top and side view of the most favourable Hydrazine configurations for $\mathrm{NH}_{3}$ production: a) N-N bond breakage step, 2 $\mathrm{N}^{*} \mathrm{H}_{2}$, b) First $\mathrm{NH}_{3}$ evolution step, $\mathrm{N}^{*} \mathrm{H}, c$ ) Second Hydrazine adsorption step, $\mathrm{N}^{*} \mathrm{HN} * \mathrm{H}+\mathrm{N}^{*} \mathrm{H}_{3}$, d) Second $\mathrm{NH}_{3}$ evolution step, $\mathrm{N}^{*} \mathrm{HN} * \mathrm{H}, e$ ) Third Hydrazine linkage step, $\mathrm{N}^{*} \mathrm{HN} * \mathrm{H}+\mathrm{N}^{*} \mathrm{H}_{2} \mathrm{NH}_{2}, f$ ) Third $\mathrm{NH}_{3}$ evolution step, $\mathrm{N}^{*} \mathrm{HN}^{*}+\mathrm{N}^{*} \mathrm{H}_{2}$ and $g$ ) Fourth $\mathrm{NH}_{3}$ and $\mathrm{N}_{2}$ evolution step, $\mathrm{N}^{*} \mathrm{~N}^{*}$. Inset, distances $(\AA)$ and angles $\left({ }^{\circ}\right)$ of interest. Carbon atom is labelled in brown, nitrogen in blue and hydrogen in white.

\section{CONCLUSIONS}

In this study, different metal-free carbonaceous materials, i.e. CNFs PS, CNFs HHT and graphite were tested in hydrazine hydrate decomposition reaction for the first time. In addition, a systematic density functional 
theory (DFT) study on $\mathrm{N}_{2} \mathrm{H}_{4}$ adsorption and decomposition mechanism was then employed to understand the role of the defects paving the pathway to the development of new and efficient carbocatalysts to be used in this reaction. A conversion of $94 \%, 71 \%$ and $65 \%$ was observed after $6 \mathrm{~h}$ of reaction for CNFs PS, CNFs HHT and graphite, respectively. For the best of our knowledge, this is the first work reported in literature which shows the ability of metal-free carbonaceous materials to decompose hydrazine hydrate. Moreover, a selectivity for $\mathrm{H}_{2}$ of the $89 \%$ at $97 \%$ of conversion was found testing CNFs-PS. The materials were also analysed using ICP and Raman spectroscopy. A correlation between the numbers of defects present in the catalysts and the initial activity of the hydrazine decomposition reaction was found. In particular, initial activity increases increasing the number of defects, i.e. CNFs-PS $>$ CNFs-HHT $>$ graphite. Correlating the $I_{D} / I_{G}$ ratio obtained by Raman spectroscopy and the initial activity, a linear correlation was found $\left(R^{2}=0.981\right)$. In addition, CNFs PS were also tested in absence of alkaline medium to understand the effect of $\mathrm{NaOH}$. The catalyst showed a conversion ( $15 \%$ conversion at $4 \mathrm{~h}$ ) lower than in presence of $\mathrm{NaOH}(94 \%$ conversion at $4 \mathrm{~h}$

In order to understand the effect of the defects on the decomposition of hydrazine, different surfaces were modelled using DFT calculation, i.e. pristine graphene, single and double vacancies, and different StoneWales defects. According to our previous studies, only SV showed an exothermic adsorption energy to our substrate, indicating that it is the only defect which participates in the reaction. Two symmetrical and one asymmetrical dehydrogenation pathways were found, but only the most favourable (symmetric hydrazine dehydrogenation) was considered in our discussion. On the most stable hydrogen production pathway, the effect of the alkaline medium was elucidated through calculations concerning the diffusion and recombination of atomic hydrogen. Indeed, the presence of $\mathrm{NaOH}$ helps extracting $\mathrm{H}$ species without additional energetic barriers, as opposed to the calculations performed in polarizable continuum medium. In addition, an incomplete decomposition pathway forming $\mathrm{N}_{2}$ and $\mathrm{NH}_{3}$ was studied and compared with the dehydrogenation one. Considering the initial dissociative adsorption, the first step of the dehydrogenation pathway is the more favourable (dissociation of the $\mathrm{N}-\mathrm{H}$ bond, $-3.00 \mathrm{eV}$ ) than the scission of the $\mathrm{N}-\mathrm{N}$ bond ($2.55 \mathrm{eV}$ ) which lead to $\mathrm{NH}_{3}$ as product. This first reaction step is crucial to define the reaction mechanisms and the computational results fully agree with the ones obtained in the experiments. Moreover, comparing two different hydrogen production pathways (with and without diffusion and recombination), we confirmed that the presence of sodium hydroxide in the experimental reaction environment can modify the energy gap between the two pathways, leading to a selectivity to $\mathrm{H}_{2}$ near $90 \%$. Overall, this work provides a complete insight of hydrazine decomposition over intrinsic elementary defects of metal-free carbonaceous catalysts. Finally, these results can be used as a raw model for the synthesis of carbocatalysts with enhanced features for the liquid phase hydrazine decomposition reaction, focusing on widening the $\Delta \mathrm{E}_{\mathrm{NN}-\mathrm{NH}}$ energy gap.

\section{REFERENCES}

[1] T.N. Veziroǧlu, S. Şahin, 21st Century's energy: Hydrogen energy system, Energy Convers. Manag. 49 (2008) $1820-1831$. https://doi.org/10.1016/j.enconman.2007.08.015.

[2] P. Nikolaidis, A. Poullikkas, A comparative overview of hydrogen production processes, Renew. Sustain. Energy Rev. 67 (2017) 597-611. https://doi.org/10.1016/j.rser.2016.09.044.

[3] M.Z. Chen W, L Z ouyang, J W Liu, X D Yao, H Wang, Z W Liu, Hydrolysis and regeneration of sodium borohydride (NaBH4) - A combination of hydrogen production and storage, J. Power Sources. 359 (2017) 400-407. https://doi.org/10.1016/j.jpowsour.2017.05.075.

I. Shown, A. Ganguly, L.C. Chen, K.H. Chen, Conducting polymer-based flexible supercapacitor, Energy Sci. Eng. 3 (2015) 1-25. https://doi.org/10.1002/ese3.50.

[5] K. Sordakis, C. Tang, L.K. Vogt, H. Junge, P.J. Dyson, M. Beller, G. Laurenczy, Homogeneous Catalysis for Sustainable Hydrogen Storage in Formic Acid and Alcohols, Chem. Rev. 118 (2018) 372-433. https://doi.org/10.1021/acs.chemrev.7b00182. 
properties on the catalytic performance, Appl. Catal. B Environ. 210 (2017) 212-222. https://doi.org/10.1016/j.apcatb.2017.03.070.

[7] M. Yadav, Q. Xu, Liquid-phase chemical hydrogen storage materials, Energy Environ. Sci. 5 (2012) 9698-9725. https://doi.org/10.1039/c2ee22937d.

[8] S.K. Singh, Q. Xu, Complete conversion of hydrous hydrazine to hydrogen at room temperature for chemical hydrogen storage, J. Am Chem. Soc. 131 (2009) 18032-18033. https://doi.org/10.1021/ja908037t.

[9] S.K. Singh, Z. Lu, Q. Xu, Temperature-Induced Enhancement of Catalytic Performance in Selective Hydrogen Generation from Hydrous Hydrazine with Ni-Based Nanocatalysts for Chemical Hydrogen Storage, Eur. J. Inorg. Chem. 2011 (2011) $2232-2237$. https://doi.org/10.1002/ejic.201100083.

[10] S.K. Singh, X.-B. Zhang, Q. Xu, Room-Temperature Hydrogen Generation from Hydrous Hydrazine for Chemical Hydrogen Storage, J. Am. Chem. Soc. 131 (2009) 9894-9895. https://doi.org/10.1021/ja903869y.

[11] S.K. Singh, A.K. Singh, K. Aranishi, Q. Xu, Noble-metal-free bimetallic nanoparticle-catalyzed selective hydrogen generation from hydrous hydrazine for chemical hydrogen storage, J. Am. Chem. Soc. 133 (2011) 19638-19641. https://doi.org/10.1021/ja208475y.

[12] R. Lan, J.T.S. Irvine, S. Tao, Ammonia and related chemicals as potential indirect hydrogen storage materials, Int. J. Hydrogen Energy. 37 (2012) 1482-1494. https://doi.org/10.1016/j.ijhydene.2011.10.004.

[13] L. Giorgi, A. Pozio, C. Bracchini, R. Giorgi, S. Turtù, H2 and H2/CO oxidation mechanism on Pt/C, Ru/C and Pt-Ru/C electrocatalysts, J. Appl. Electrochem. 31 (2001) 325-334. https://doi.org/10.1023/A:1017595920726.

[14] M. Pravica, L. Bai, Y. Liu, Hydrazine at high pressure, Chem. Phys. Lett. 555 (2013) 115-118. https://doi.org/https://doi.org/10.1016/j.cplett.2012.10.079.

[15] A.S. Shteinberg, High-Temperature Decomposition and Thermal Explosion of Liquid Propellant Components: Hydrogen Peroxide and Hydrazine BT - Fast Reactions in Energetic Materials: High-Temperature Decomposition of Rocket Propellants and Explosives, in: A.S. Shteinberg (Ed.), Springer Berlin Heidelberg, Berlin, Heidelberg, 2008: pp. 173-198. https://doi.org/10.1007/978-3-540-78861-4_11.

[16] J.K. Norskov, C.H. Christensen, Toward Efficient Hydrogen Production at Surfaces, Science (80-. ). 312 (2006) 1322 LP - 1323. https://doi.org/10.1126/science.1127180.

[17] S.E. Wood, J.T. Bryant, Decomposition of Hydrazine on Shell 405 Catalyst at High Presure, Prod. R\&D. 12 (1973) 117-122. https://doi.org/10.1021/i360046a004.

[18] T.G. Soares Neto, A.J.G. Cobo, G.M. Cruz, Textural properties evolution of Ir and Ru supported on alumina catalysts during hydrazine decomposition in satellite thruster, Appl. Catal. A Gen. 250 (2003) 331-340. https://doi.org/https://doi.org/10.1016/S0926860X(03)00301-6.

[19] J.P. Contour, G. Pannetier, Hydrazine decomposition over a supported iridium catalyst, J. Catal. 24 (1972) $434-445$

[20] R. Maurel, J.C. Menezo, Catalytic decomposition of 15N-labeled hydrazine on alumina-supported metals, J. Catal. 51 (1978) $293-295$.

[21] P.-X. Zhang, Y.-G. Wang, Y.-Q. Huang, T. Zhang, G.-S. Wu, J. Li, Density functional theory investigations on the catalytic mechanisms of hydrazine decompositions on Ir (1 11 1), Catal. Today. 165 (2011) 80-88.

[22] A.K. Singh, M. Yadav, K. Aranishi, Q. Xu, Temperature-induced selectivity enhancement in hydrogen generation from Rh-Ni nanoparticlecatalyzed decomposition of hydrous hydrazine, Int. J. Hydrogen Energy. 37 (2012) 18915-18919. https://doi.org/10.1016/j.ijhydene.2012.09.104.

[23] L. Zhou, X. Luo, L. Xu, C. Wan, M. Ye, Pt-ni nanoalloys for H2 generation from hydrous hydrazine, Catalysts. 10 (2020). https://doi.org/10.3390/catal10080930.

[24] L. He, B. Liang, L. Li, X. Yang, Y. Huang, A. Wang, X. Wang, T. Zhang, Cerium-oxide-modified nickel as a non-noble metal catalyst for selective decomposition of hydrous hydrazine to hydrogen, Acs Catal. 5 (2015) 1623-1628.

[25] M. Zheng, R. Cheng, X. Chen, N. Li, L. Li, X. Wang, T. Zhang, A novel approach for CO-free H2 production via catalytic decomposition of hydrazine, Int. J. Hydrogen Energy. 30 (2005) 1081-1089. https://doi.org/10.1016/j.ijhydene.2004.09.014.

[26] S.K. Singh, Q. Xu, Nanocatalysts for hydrogen generation from hydrazine, Catal. Sci. Technol. 3 (2013) 1889-1900. https://doi.org/10.1039/c3cy00101f.

[27] Y. Cheng, X. Wu, H. Xu, Catalytic decomposition of hydrous hydrazine for hydrogen production, Sustain. Energy Fuels. 3 (2019) 343-365. https://doi.org/10.1039/c8se00538a.

[28] Z. Zhang, S. Zhang, Q. Yao, X. Chen, Z.-H. Lu, Controlled Synthesis of MOF-Encapsulated NiPt Nanoparticles toward Efficient and Complete Hydrogen Evolution from Hydrazine Borane and Hydrazine, Inorg. Chem. 56 (2017) 11938-11945.

https://doi.org/10.1021/acs.inorgchem.7b01910.

[29] S.J. Cho, J. Lee, Y.S. Lee, D.P. Kim, Characterization of Iridium Catalyst for Decomposition of Hydrazine Hydrate for Hydrogen Generation, 
[30] H.-L. Jiang, S.K. Singh, J.-M. Yan, X.-B. Zhang, Q. Xu, Liquid-Phase Chemical Hydrogen Storage: Catalytic Hydrogen Generation under Ambient Conditions, ChemSusChem. 3 (2010) 541-549. https://doi.org/https://doi.org/10.1002/cssc.201000023.

[31] P.Z. Li, Q. Xu, Metal-nanoparticle catalyzed hydrogen generation from liquid-phase chemical hydrogen storage materials, J. Chinese Chem. Soc. 59 (2012) 1181-1189. https://doi.org/10.1002/jccs.201200033.

[32] Y.-P. Qiu, H. Yin, H. Dai, L.-Y. Gan, H.-B. Dai, P. Wang, Tuning the Surface Composition of Ni/meso-CeO2 with Iridium as an Efficient Catalyst for Hydrogen Generation from Hydrous Hydrazine, Chem. - A Eur. J. 24 (2018) 4902-4908. https://doi.org/https://doi.org/10.1002/chem.201705923.

[33] Y.-Y. Jiang, H.-B. Dai, Y.-J. Zhong, D.-M. Chen, P. Wang, Complete and Rapid Conversion of Hydrazine Monohydrate to Hydrogen over Supported Ni-Pt Nanoparticles on Mesoporous Ceria for Chemical Hydrogen Storage, Chem. - A Eur. J. 21 (2015) 15439-15445. https://doi.org/https://doi.org/10.1002/chem.201502421.

[34] P. Zhao, N. Cao, J. Su, W. Luo, G. Cheng, Nilr Nanoparticles Immobilized on the Pores of MIL-101 as Highly Efficient Catalyst toward Hydrogen Generation from Hydrous Hydrazine, ACS Sustain. Chem. Eng. 3 (2015) 1086-1093. https://doi.org/10.1021/acssuschemeng.5b00009.

[35] Y.B. Jang, T.H. Kim, M.H. Sun, J. Lee, S.J. Cho, Preparation of iridium catalyst and its catalytic activity over hydrazine hydrate decomposition for hydrogen production and storage, Catal. Today. 146 (2009) 196-201.

[36] X. Du, P. Cai, W. Luo, G. Cheng, Facile synthesis of P-doped Rh nanoparticles with superior catalytic activity toward dehydrogenation of hydrous hydrazine, Int. J. Hydrogen Energy. 42 (2017) 6137-6143. https://doi.org/https://doi.org/10.1016/j.ijhydene.2016.12.049.

[37] N. Cao, L. Yang, H. Dai, T. Liu, J. Su, X. Wu, W. Luo, G. Cheng, Immobilization of Ultrafine Bimetallic Ni-Pt Nanoparticles Inside the Pores of Metal-Organic Frameworks as Efficient Catalysts for Dehydrogenation of Alkaline Solution of Hydrazine, Inorg. Chem. 53 (2014) 1012210128. https://doi.org/10.1021/ic5010352.

[38] R. Jiang, X. Qu, F. Zeng, Q. Li, X. Zheng, Z. Xu, J. Peng, MOF-74-immobilized ternary RhNiP nanoparticles as highly efficient hydrous hydrazine dehydrogenation catalysts in alkaline solutions, Int. J. Hydrogen Energy. 44 (2019) 6383-6391. https://doi.org/https://doi.org/10.1016/j.ijhydene.2019.01.117.

[39] L. He, B. Liang, Y. Huang, T. Zhang, Design strategies of highly selective nickel catalysts for H2 production via hydrous hydrazine decomposition: a review, Natl. Sci. Rev. 5 (2018) 356-364. https://doi.org/10.1093/nsr/nwx123.

[40] L. He, Y. Huang, X.Y. Liu, L. Li, A. Wang, X. Wang, C.-Y. Mou, T. Zhang, Structural and catalytic properties of supported Ni-Ir alloy catalysts for $\mathrm{H} 2$ generation via hydrous hydrazine decomposition, Appl. Catal. B Environ. 147 (2014) 779-788.

[41] Y. Qiu, H. Yin, H. Dai, L. Gan, H. Dai, P. Wang, Tuning the Surface Composition of Ni/meso-CeO2 with Iridium as an Efficient Catalyst for Hydrogen Generation from Hydrous Hydrazine, Chem. Eur. J. 24 (2018) 4902-4908.

[42] J. Chen, Q. Yao, J. Zhu, X. Chen, Z.-H. Lu, Rh-Ni nanoparticles immobilized on Ce (OH) CO3 nanorods as highly efficient catalysts for hydrogen generation from alkaline solution of hydrazine, Int. J. Hydrogen Energy. 41 (2016) 3946-3954.

[43] Y. Jiang, H. Dai, Y. Zhong, D. Chen, P. Wang, Complete and rapid conversion of hydrazine monohydrate to hydrogen over supported Ni-Pt nanoparticles on mesoporous ceria for chemical hydrogen storage, Chem. Eur. J. 21 (2015) 15439-15445.

[44] H. Wang, L. Wu, Y. Wang, X. Li, Y. Wang, Facile synthesis of Ni nanoparticles from triangular Ni (HCO3) 2 nanosheets as catalysts for hydrogen generation from hydrous hydrazine, Catal. Commun. 100 (2017) 33-37.

[45] S.N. Oliaee, C. Zhang, S.Y. Hwang, H.M. Cheung, Z. Peng, Hydrogen production via hydrazine decomposition on model platinum-nickel nanocatalyst with a single (111) facet, J. Phys. Chem. C. 120 (2016) 9764-9772. https://doi.org/10.1021/acs.jpcc.6b00815.

[46] J. Wang, X.-B. Zhang, Z.-L. Wang, L.-M. Wang, Y. Zhang, Rhodium-nickel nanoparticles grown on graphene as highly efficient catalyst for complete decomposition of hydrous hydrazine at room temperature for chemical hydrogen storage, Energy Environ. Sci. 5 (2012) 6885. https://doi.org/10.1039/c2ee03344e.

[47] U. Sikander, S. Sufian, M.A. Salam, A review of hydrotalcite based catalysts for hydrogen production systems, Int. J. Hydrogen Energy. 42 (2017) 19851-19868. https://doi.org/10.1016/j.ijhydene.2017.06.089.

[48] Z. Liu, J. Li, S. Xue, S. Zhou, K. Qu, Y. Li, W. Cai, Pt/Mo2C heteronanosheets for superior hydrogen evolution reaction, J. Energy Chem. 47 (2020) 317-323. https://doi.org/10.1016/j.jechem.2020.02.005.

[49] C. Li, J.B. Baek, Recent Advances in Noble Metal (Pt, Ru, and Ir)-Based Electrocatalysts for Efficient Hydrogen Evolution Reaction, ACS Omega. 5 (2020) 31-40. https://doi.org/10.1021/acsomega.9b03550.

[50] X. Zhou, Y. Huang, W. Xing, C. Liu, J. Liao, T. Lu, High-quality hydrogen from the catalyzed decomposition of formic acid by Pd-Au/C and PdAg/C, Chem. Commun. (2008) 3540-3542. https://doi.org/10.1039/b803661f.

[51] J.A. Herron, J. Scaranto, P. Ferrin, S. Li, M. Mavrikakis, Trends in formic acid decomposition on model transition metal surfaces: A density 
functional theory study, ACS Catal. 4 (2014) 4434-4445. https://doi.org/10.1021/cs500737p.

[52] N. Gupta, O. Khavryuchenko, A. Villa, D. Su, Metal-Free Oxidation of Glycerol over Nitrogen-Containing Carbon Nanotubes, ChemSusChem. 10 (2017) 3030-3034. https://doi.org/10.1002/cssc.201700940.

[53] P. Veerakumar, P. Thanasekaran, T. Subburaj, K.-C. Lin, A Metal-Free Carbon-Based Catalyst: An Overview and Directions for Future Research, C. 4 (2018) 54. https://doi.org/10.3390/c4040054.

[54] M.M. Titirici, M. Antonietti, Chemistry and materials options of sustainable carbon materials made by hydrothermal carbonization, Chem Soc. Rev. 39 (2010) 103-116. https://doi.org/10.1039/b819318p.

[55] G. Mestl, N.I. Maksimova, N. Keller, V. V. Roddatis, R. Schlögl, Carbon Nanofilaments in Heterogeneous Catalysis: An Industrial Application for New Carbon Materials?, Angew. Chemie - Int. Ed. 40 (2001) 2066-2068. https://doi.org/10.1002/15213773(20010601)40:11<2066::AID-ANIE2066>3.0.CO;2-I.

[56] P.N. Optics, N. York, Surface-Modified Carbon Nanotubes, 322 (2008) 73-78.

[57] J. Zhang, D.S. Su, R. Blume, R. Schlögl, R. Wang, X. Yang, A. Gajović, Surface chemistry and catalytic reactivity of a nanodiamond in the steam-free dehydrogenation of ethylbenzene, Angew. Chemie - Int. Ed. 49 (2010) 8640-8644. https://doi.org/10.1002/anie.201002869.

[58] J.H. Yang, G. Sun, Y. Gao, H. Zhao, P. Tang, J. Tan, A.H. Lu, D. Ma, Direct catalytic oxidation of benzene to phenol over metal-free graphene-based catalyst, Energy Environ. Sci. 6 (2013) 793-798. https://doi.org/10.1039/c3ee23623d.

[59] D.R. Dreyer, H.P. Jia, C.W. Bielawski, Graphene oxide: A convenient carbocatalyst for facilitating oxidation and hydration reactions, Angew. Chemie - Int. Ed. 49 (2010) 6813-6816. https://doi.org/10.1002/anie.201002160.

[60] M.A. Patel, F. Luo, M.R. Khoshi, E. Rabie, Q. Zhang, C.R. Flach, R. Mendelsohn, E. Garfunkel, M. Szostak, H. He, P-Doped Porous Carbon as Metal Free Catalysts for Selective Aerobic Oxidation with an Unexpected Mechanism, ACS Nano. 10 (2016) $2305-2315$. https://doi.org/10.1021/acsnano.5b07054.

[61] A. Primo, F. Neatu, M. Florea, V. Parvulescu, H. Garcia, Graphenes in the absence of metals as carbocatalysts for selective acetylene hydrogenation and alkene hydrogenation, Nat. Commun. 5 (2014) 1-9. https://doi.org/10.1038/ncomms6291.

[62] Y. Gao, D. Ma, C. Wang, J. Guan, X. Bao, Reduced graphene oxide as a catalyst for hydrogenation of nitrobenzene at room temperature, Chem. Commun. 47 (2011) 2432-2434. https://doi.org/10.1039/c0cc04420b.

[63] I. Barlocco, S. Capelli, X. Lu, S. Tumiati, N. Dimitratos, A. Roldan, A. Villa, Role of defects in carbon materials during metal-free formic acid dehydrogenation, Nanoscale. (2020) 22768-22777. https://doi.org/10.1039/d0nr05774f.

[64] X. Lu, A. Roldan, Are Carbon-Based Materials Good Supports for the Catalytic Reforming of Ammonia?, J. Phys. Chem. C. (2021). https://doi.org/10.1021/acs.jpcc.1c03996.

[65] F. Zheng, H. Dong, Y. Ji, Y. Li, Adsorption and catalytic decomposition of hydrazine on metal-free SiC 3 siligraphene, Appl. Surf. Sci. 469 (2019) 316-324. https://doi.org/10.1016/j.apsusc.2018.11.002.

[66] C. Gojon, B. Dureault, Spectrophotometric study of the reaction between hydrazine and p.dimethylaminobenzaldehyde, J. Nucl. Sci. Technol. 33 (1996) 731-735. https://doi.org/10.1080/18811248.1996.9731989.

[67] W.D. Basson, J.F. Van Staden, Low-level determination of hydrazine in boiler feed water with an unsegmented high-speed continuousflow system, Analyst. 103 (1978) 998-1001. https://doi.org/10.1039/AN9780300998.

[68] G. Kresse, J. Furthmüller, Efficient iterative schemes for ab initio total-energy calculations using a plane-wave basis set, Phys. Rev. B Condens. Matter Mater. Phys. 54 (1996) 11169-11186. https://doi.org/10.1103/PhysRevB.54.11169.

[69] G. Kresse, Ab initio molecular dynamics for liquid metals, J. Non. Cryst. Solids. 192-193 (1995) 222-229. https://doi.org/10.1016/00223093(95)00355-X

[70] B. Hammer, L.B. Hansen, J.K. Nørskov, Improved adsorption energetics within density-functional theory using revised Perdew-BurkeErnzerhof functionals, Phys. Rev. B. 59 (1999) 7413-7421. https://doi.org/10.1103/PhysRevB.59.7413.

[71] N.D. Mermin, Thermal properties of the inhomogeneous electron gas, Phys. Rev. 137 (1965) 1-3. https://doi.org/10.1103/PhysRev.137.A1441.

[72] R. Sure, J. Antony, S. Grimme, Blind prediction of binding affinities for charged supramolecular host-guest systems: achievements and shortcomings of DFT-D3, J. Phys. Chem. B. 118 (2014) 3431-3440.

[73] S. Ehrlich, J. Moellmann, W. Reckien, T. Bredow, S. Grimme, System-Dependent Dispersion Coefficients for the DFT-D3 Treatment of Adsorption Processes on Ionic Surfaces, ChemPhysChem. 12 (2011) 3414-3420.

[74] H. Fang, A. Roldan, C. Tian, Y. Zheng, X. Duan, K. Chen, L. Ye, S. Leoni, Y. Yuan, Structural tuning and catalysis of tungsten carbides for the regioselective cleavage of C-O bonds, J. Catal. 369 (2019) 283-295. https://doi.org/10.1016/j.jcat.2018.11.020. 
[75] X. Lu, S. Francis, D. Motta, N. Dimitratos, A. Roldan, Mechanistic study of hydrazine decomposition on Ir(111), Phys. Chem. Chem. Phys. 22 (2020) 3883-3896. https://doi.org/10.1039/c9cp06525c.

[76] E. Nowicka, S. Althahban, T.D. Leah, G. Shaw, D. Morgan, C.J. Kiely, A. Roldan, G.J. Hutchings, Benzyl alcohol oxidation with Pd-Zn/TiO2: computational and experimental studies, Sci. Technol. Adv. Mater. 20 (2019) 367-378. https://doi.org/10.1080/14686996.2019.1598237.

[77] M.G. Quesne, A. Roldan, N.H. De Leeuw, C.R.A. Catlow, Carbon dioxide and water co-adsorption on the low-index surfaces of TiC, VC, ZrC and NbC: A DFT study, Phys. Chem. Chem. Phys. 21 (2019) 10750-10760. https://doi.org/10.1039/c9cp00924h.

[78] R. Sundararaman, K. Schwarz, Evaluating continuum solvation models for the electrode-electrolyte interface: Challenges and strategies for improvement, J. Chem. Phys. 146 (2017). https://doi.org/10.1063/1.4976971.

[79] K. Mathew, R. Sundararaman, K. Letchworth-Weaver, T.A. Arias, R.G. Hennig, Implicit solvation model for density-functional study of nanocrystal surfaces and reaction pathways, J. Chem. Phys. 140 (2014). https://doi.org/10.1063/1.4865107.

[80] J.D. Pack, H.J. Monkhorst, "special points for Brillouin-zone integrations"-a reply, Phys. Rev. B. 16 (1977) $1748-1749$. https://doi.org/10.1103/PhysRevB.16.1748.

[81] Y.W. Tan, H.L. Stormer, P. Kim, K.S. Novoselov, M.L. Cohen, S.G. Louie, X. Wang, L. Zhang, S. Lee, H. Dai, Y. Kobayashi, K. Fukui, M. Fujita, G. Dresselhaus, M.S. Dresselhaus, M.A. Pimenta, B.R.A. Neves, A. Jorio, Y. Zhang, M. Mailman, P.M. Ajayan, S.K. Nayak, C.H. Park, Y.W. Son, S.P. Lu, S. Piscanec, A.C. Ferrari, G. Dobrik, P. Lambin, A. Oberlin, T. Solid, K. Suenaga, S. lijima, P. Hermet, V. Meunier, L. Henrard, D. Gunlycke, C.T. White, S. Chen, B.I. Yakobson, S. Gradecak, Graphene at the Edge: Stability and Dynamics, Science (80-. ). 323 (2009) 17051708 .

[82] G. Henkelman, A. Arnaldsson, H. Jónsson, A fast and robust algorithm for Bader decomposition of charge density, Comput. Mater. Sci. 36 (2006) 354-360. https://doi.org/10.1016/j.commatsci.2005.04.010.

[83] M. Yu, D.R. Trinkle, Accurate and efficient algorithm for Bader charge integration, J. Chem. Phys. 134 (2011) 1-8. https://doi.org/10.1063/1.3553716.

[84] P.L.A. Popelier, On the full topology of the Laplacian of the electron density, Coord. Chem. Rev. 197 (2000) 169-189. https://doi.org/10.1016/s0010-8545(99)00189-7.

[85] D. Vega, D. Almeida, AIM-UC: An application for QTAIM analysis, J. Comput. Methods Sci. Eng. 14 (2014) $131-136$.

[86] V.A. Borodin, T.T. Vehviläinen, M.G. Ganchenkova, R.M. Nieminen, Hydrogen transport on graphene: Competition of mobility and desorption, Phys. Rev. B - Condens. Matter Mater. Phys. 84 (2011) 1-15. https://doi.org/10.1103/PhysRevB.84.075486.

[87] F. Tuinstra, J.L. Koenig, Raman Spectrum of Graphite, J. Chem. Phys. 53 (1970) 1126-1130. https://doi.org/10.1063/1.1674108.

[88] C.R. Wick, T. Clark, On bond-critical points in QTAIM and weak interactions, J. Mol. Model. 24 (2018) 1-9. https://doi.org/10.1007/s00894018-3684-x.

[89] L. Ma, J.M. Zhang, K.W. Xu, V. Ji, A first-principles study on gas sensing properties of graphene and Pd-doped graphene, Appl. Surf. Sci. 343 (2015) 121-127. https://doi.org/10.1016/j.apsusc.2015.03.068.

[90] X.Y. Liu, J.M. Zhang, K.W. Xu, V. Ji, Improving SO 2 gas sensing properties of graphene by introducing dopant and defect: A first-principles study, Appl. Surf. Sci. 313 (2014) 405-410. https://doi.org/10.1016/j.apsusc.2014.05.223.

[91] S. Yang, Z. Lan, H. Xu, G. Lei, W. Xie, Q. Gu, A First-Principles Study on Hydrogen Sensing Properties of Pristine and Mo-Doped Graphene, J. Nanotechnol. 2018 (2018). https://doi.org/10.1155/2018/2031805.

[92] D.C. de Oliveira, W.O. Silva, M. Chatenet, F.H.B. Lima, NiOx-Pt/C nanocomposites: Highly active electrocatalysts for the electrochemical oxidation of hydrazine, Appl. Catal. B Environ. 201 (2017) 22-28. https://doi.org/https://doi.org/10.1016/j.apcatb.2016.08.007.

[93] B. Luo, T. Wu, L. Zhang, F. Diao, Y. Zhang, L. Ci, J. Ulstrup, J. Zhang, P. Si, Monometallic nanoporous nickel with high catalytic performance towards hydrazine electro-conversion and its DFT calculations, Electrochim. Acta. 317 (2019) 449-458.

https://doi.org/https://doi.org/10.1016/j.electacta.2019.05.123.

[94] X. Lu, S. Francis, D. Motta, N. Dimitratos, A. Roldan, Mechanistic study of hydrazine decomposition on Ir (111), Phys. Chem. Chem. Phys. 22 (2020) 3883-3896.

[95] S.S. Tafreshi, A. Roldan, N.H. de Leeuw, Density functional theory calculations of the hydrazine decomposition mechanism on the planar and stepped Cu (111) surfaces, Phys. Chem. Chem. Phys. 17 (2015) 21533-21546.

[96] M.K. Agusta, H. Kasai, First principles investigations of hydrazine adsorption conformations on Ni (111) surface, Surf. Sci. 606 (2012) 766771.

[97] H. Yin, Y.-P. Qiu, H. Dai, L.-Y. Gan, H.-B. Dai, P. Wang, Understanding of selective H2 generation from hydrazine decomposition on Ni (111) surface, J. Phys. Chem. C. 122 (2018) 5443-5451.

[98] M.K. Agusta, M. David, H. Nakanishi, H. Kasai, Hydrazine (N2H4) adsorption on Ni (1 0 0)-density functional theory investigation, Surf. Sci. 
604 (2010) 245-251.

[99] M.K. Agusta, W.A. Diño, M. David, H. Nakanishi, H. Kasai, Theoretical study of hydrazine adsorption on Pt (111): Anti or cis?, Surf. Sci. 605 (2011) 1347-1353.

[100] D. Zhao, D. Lü, Y. Zang, X. Zhao, Spillover in heterogeneous catalysis, Prog. Chem. 9 (1997) 759-788.

[101] C.P. Herrero, R. Ramírez, Vibrational properties and diffusion of hydrogen on graphene, Phys. Rev. B - Condens. Matter Mater. Phys. 79 (2009) 1-8. https://doi.org/10.1103/PhysRevB.79.115429.

[102] Y. Lei, S.A. Shevlin, W. Zhu, Z.X. Guo, Hydrogen-induced magnetization and tunable hydrogen storage in graphitic structures, Phys. Rev. B Condens. Matter Mater. Phys. 77 (2008) 1-8. https://doi.org/10.1103/PhysRevB.77.134114.

[103] L. Chen, A.C. Cooper, G.P. Pez, H. Cheng, Mechanistic study on hydrogen spillover onto graphitic carbon materials, J. Phys. Chem. C. 111 (2007) 18995-19000. https://doi.org/10.1021/jp074920g.

[104] E. Skúlason, V. Tripkovic, M.E. Björketun, S. Gudmundsdóttir, G. Karlberg, J. Rossmeisl, T. Bligaard, H. Jónsson, J.K. Nørskov, Modeling the electrochemical hydrogen oxidation and evolution reactions on the basis of density functional theory calculations, J. Phys. Chem. C. 114 (2010) 18182-18197. https://doi.org/10.1021/jp1048887.

[105] L. Liu, M. Qing, Y. Wang, S. Chen, Defects in Graphene: Generation, Healing, and Their Effects on the Properties of Graphene: A Review, J. Mater. Sci. Technol. 31 (2015) 599-606. https://doi.org/https://doi.org/10.1016/j.jmst.2014.11.019.

[106] F. Banhart, J. Kotakoski, A. V. Krasheninnikov, Structural defects in graphene, ACS Nano. 5 (2011) 26-41. https://doi.org/10.1021/nn102598m.

[107] S.S. Tafreshi, A. Roldan, N.H. De Leeuw, Density Functional Theory Study of the Adsorption of Hydrazine on the Perfect and Defective Copper (100), (110), and (111) Surfaces, J. Phys. Chem. C. 118 (2014) 26103-26114. https://doi.org/10.1021/jp5078664. 